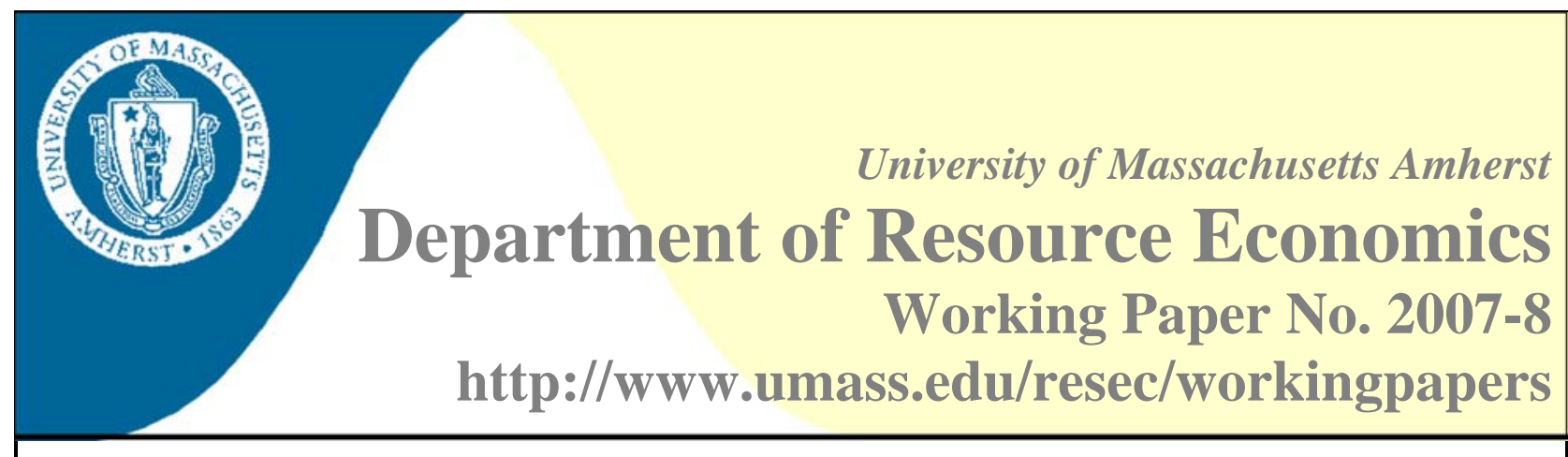

\title{
A Multi-Factorial Risk Prioritization Framework for Food-borne Pathogens
}

\author{
Spencer J. Henson ${ }^{1}$, Julie A. Caswell ${ }^{2}$, John A. L. Cranfield ${ }^{3}$, Aamir Fazil ${ }^{4}$,
} Valerie J. Davidson ${ }^{5}$, Sven M. Anders ${ }^{6}$ and Claudia Schmidt ${ }^{7}$

Abstract:

To lower the incidence of human food-borne disease, experts and stakeholders have urged the development of a science- and risk-based management system in which food-borne hazards are analyzed and prioritized. A literature review shows that most approaches to risk prioritization developed to date are based on measures of health outcomes and do not systematically account for other factors that may be important to decision making.

(Continued on next page)

${ }^{1}$ Spencer J. Henson, Department of Food, Agricultural and Resource Economics

University of Guelph, Guelph, Ontario N1G 2W1 Canada

E: shenson@uoguelph.ca P: 519-824-4120 (extension 53134) F: 519-767-1510

${ }^{2}$ Julie A. Caswell, Department of Resource Economics

University of Massachusetts, 215 Stockbridge Hall

80 Campus Center Way, Amherst, MA 01003

E: caswell@resecon.umass.edu P: 413-545-5735 F: 413-545-5853

${ }^{3}$ John A. L. Cranfield, Department of Food, Agricultural and Resource Economics

University of Guelph, Guelph, Ontario N1G 2W1 Canada

E: jcranfie@uoguelph.ca P: 519-824-4120 (extension 53708) F: 519-767-1510

${ }^{4}$ Aamir Frazil, Public Health Agency of Canada

160 Research Lane, Unit 206, Guelph, Ontario N1G 5B2 Canada

E: aamir_fazil@phac-aspc.gc.ca P: 519-826-2370 F: 519-826-2367

${ }^{5}$ Valerie J. Davidson, School of Engineering

University of Guelph, Guelph, Ontario N1G 2W1 Canada

E: vdavidso@uoguelph.ca P: 519-824-4120 (extension 54367) F: 519-836-0227

${ }^{6}$ Sven M. Anders, Department of Rural Economy

University of Alberta, Edmonton, AB T6G 2H1 Canada

E: sven.anders@ualberta.ca P: 780-492-5453 F: 780-492-0268

${ }^{7}$ Claudia Schmidt, Department of Food, Agricultural and Resource Economics

University of Guelph, Guelph, Ontario N1G 2W1 Canada

E: schmidtc@uoguelph.ca P: 519-824-4120 (extension 58343) F: 519-767-1510 


\section{University of Massachusetts Amherst
Department of Resource Economics
Working Paper No. 2007-8 \\ A Multi-Factorial Risk Prioritization Framework for Food-borne Pathogens (cont'd)}

Abstract (continued):

The Multi-Factorial Risk Prioritization Framework developed here considers four factors that may be important to risk managers: public health, consumer risk perceptions and acceptance, market-level impacts, and social sensitivity. The framework is based on the systematic organization and analysis of data on these multiple factors. The basic building block of the information structure is a three-dimensional cube based on pathogen-food-factor relationships. Each cell of the cube has an information card associated with it and data from the cube can be aggregated along different dimensions.

The framework is operationalized in three stages, with each stage adding another dimension to decision-making capacity. The first stage is the information cards themselves that provide systematic information that is not preprocessed or aggregated across factors. The second stage maps the information on the various information cards into cobweb diagrams that create a graphical profile of, for example, a food-pathogen combination with respect to each of the four risk prioritization factors. The third stage is formal multi-criteria decision analysis in which decision makers place explicit values on different criteria in order to develop risk priorities.

The process outlined above produces a 'List A' of priority food-pathogen combinations according to some aggregate of the four risk prioritization factors. This list is further vetted to produce 'List B', which brings in feasibility analysis by ranking those combinations where practical actions that have a significant impact are feasible. Foodpathogen combinations where not enough is known to identify any or few feasible interventions are included in 'List C'. 'List C' highlights areas with significant uncertainty where further research may be needed to enhance the precision of the risk prioritization process. The separation of feasibility and uncertainty issues through the use of 'Lists A, B, and C' allows risk managers to focus separately on distinct dimensions of the overall prioritization.

The Multi-Factorial Risk Prioritization Framework provides a flexible instrument that compares and contrasts risks along four dimensions. Use of the framework is an iterative process. It can be used to establish priorities across pathogens for a particular food, across foods for a particular pathogen and/or across specific food-pathogen combinations. This report provides a comprehensive conceptual paper that forms the basis for a wider process of consultation and for case studies applying the framework.

Keywords: Risk analysis, risk prioritization, food-borne pathogens, benefits and costs

JEL Classification: I18, L51, Q00, K32, H11

This paper is also published as International Food Economy Research Group (InFERG) Working Paper 9, University of Guelph. 


\title{
A MUlti-FACtORIal RISK PRIORITIZATION FRAMEWORK FOR FOOD-BORNE PATHOGENS
}

\author{
SPENCER HENSON \\ JULIE CASWELL \\ JOHN CRANFIELD \\ AAMIR FAZIL \\ VALERIE DAVIDSON \\ SVEN ANDERS \\ Claudia SCHMIDT
}




\section{CONTENTS}

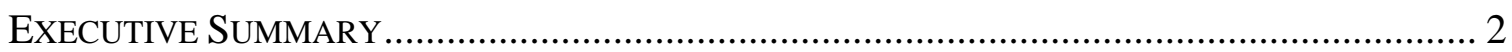

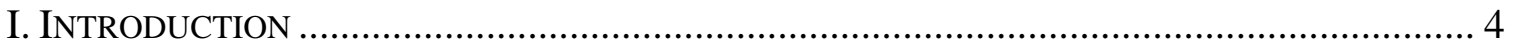

II. LITERATURE REVIEW AND PREVIOUS WORK............................................................... 7

III. Multi-FACTORIAL RISK PRIORITIZATION - OVERVIEW OF THE PROCESS .................... 15

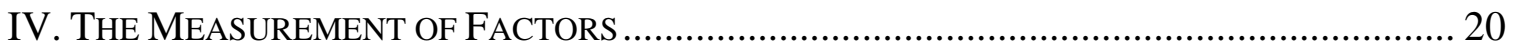

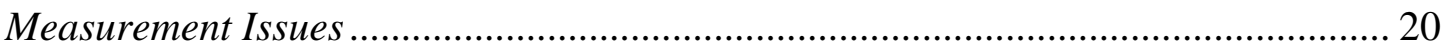

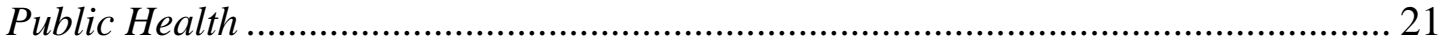

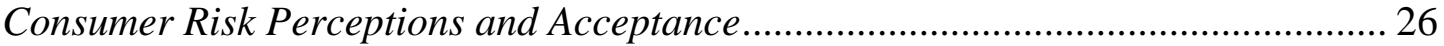

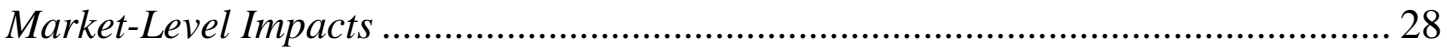

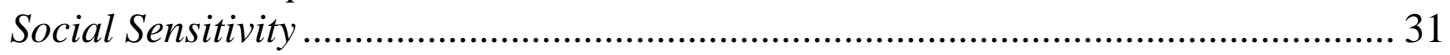

V. AGGREGATION AND OPERATIONALIZATION OF THE FRAMEWORK............................... 32

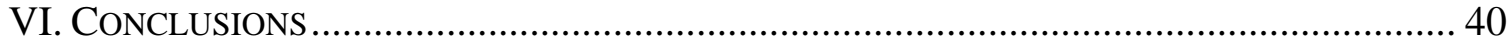

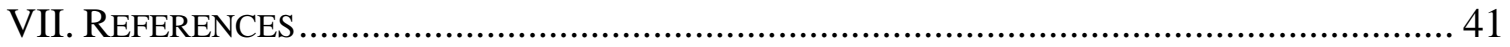




\section{A MULTI-FACTORIAL RISK PRIORITIZATION FRAMEWORK FOR FOOD-BORNE PATHOGENS}

\section{EXECUTIVE SUMMARY}

To lower the incidence of human food-borne disease, experts and stakeholders have urged the development of a science- and risk-based management system in which foodborne hazards are analyzed and prioritized. A literature review shows that most approaches to risk prioritization developed to date are based on measures of health outcomes and do not systematically account for other factors that may be important to decision making.

The Multi-Factorial Risk Prioritization Framework developed here considers four factors that may be important to risk managers: public health, consumer risk perceptions and acceptance, market-level impacts, and social sensitivity. The framework is based on the systematic organization and analysis of data on these multiple factors. The basic building block of the information structure is a three-dimensional cube based on pathogen-foodfactor relationships. Each cell of the cube has an information card associated with it and data from the cube can be aggregated along different dimensions.

The framework is operationalized in three stages, with each stage adding another dimension to decision-making capacity. The first stage is the information cards themselves that provide systematic information that is not pre-processed or aggregated across factors. The second stage maps the information on the various information cards into cobweb diagrams that create a graphical profile of, for example, a food-pathogen combination with respect to each of the four risk prioritization factors. The third stage is formal multi-criteria decision analysis in which decision makers place explicit values on different criteria in order to develop risk priorities.

The process outlined above produces a 'List A' of priority food-pathogen combinations according to some aggregate of the four risk prioritization factors. This list is further vetted to produce 'List B', which brings in feasibility analysis by ranking those combinations where practical actions that have a significant impact are feasible. Foodpathogen combinations where not enough is known to identify any or few feasible interventions are included in 'List C'. 'List C' highlights areas with significant uncertainty where further research may be needed to enhance the precision of the risk prioritization process. The separation of feasibility and uncertainty issues through the use

of 'Lists A, B, and C' allows risk managers to focus separately on distinct dimensions of the overall prioritization.

The Multi-Factorial Risk Prioritization Framework provides a flexible instrument that compares and contrasts risks along four dimensions. Use of the framework is an iterative process. It can be used to establish priorities across pathogens for a particular food, across foods for a particular pathogen and/or across specific food-pathogen combinations. This report provides a comprehensive conceptual paper that forms the basis for a wider process of consultation and for case studies applying the framework. 


\section{KEYWORDS}

Risk analysis, risk prioritization, food-borne pathogens, benefits and costs

\section{JEL (JOURNAL OF ECONOMIC LITERATURE) CLASSIFICATION I18, L51, Q00, K32, H11}

\section{ACKNOWLEDGEMENTS}

This research was supported by a grant from Health Canada and the Public Health Agency of Canada. Additional support was provided by the University of Guelph and by a United States Department of Agriculture: Cooperative State Research, Education, and Extension Service Special Grant to the Food Marketing Policy Center, University of Connecticut, and by a subcontract to the University of Massachusetts Amherst. 


\section{A MULTI-FACTORIAL RISK PRIORITIZATION FRAMEWORK FOR FOOD-BORNE PATHOGENS}

\section{INTRODUCTION:}

The spectrum and prevalence of microbial hazards in the food supply chain have led to increased concerns among researchers, policy-makers and, above all, consumers regarding the safety of food and the economic and social costs associated with foodborne disease. Internationally, governments and non-governmental organizations are undertaking efforts for the development of new and more efficient food safety controls directed at specific food-borne hazards in order to improve public health.

To lower the incidence of human food-borne disease, experts and stakeholders have urged the development of a science- and risk-based management system in which foodborne hazards are analyzed and prioritized. In this context, intervention can then be pursued on the basis of the best available data to reduce risk to public health. Moreover, such a risk management system requires broad understanding of numerous risk factors along the supply chain and the ability to systematically target and make preventive interventions in an effective and efficient manner.

Recent empirical evidence points to the need for improved understanding of integrated food-borne risk prioritization and management processes that are designed to encompass the complexity of the effects of food-borne hazards on societies. Cumulatively, concerns from different scientific disciplines and from public and private stakeholders indicate that the science- and risk-based prioritization of microbial hazards in foods must recognize the fact that any decision-making and risk ranking process operates within a socioeconomic and political milieu and should aim at effective food risk mitigation strategies that are in the public interest.

With developments in microbial risk analysis techniques in recent years, there are now better monitoring and surveillance procedures available for sound risk assessments of food-borne hazards. However, a framework that systematically prioritizes and selects those hazards and/or foods that pose the greatest threat to human health, and aids in the efficient and effective prevention of food-borne illnesses, requires decision-making tools and data that, although with some exceptions, are not currently available. In order to achieve this objective a more integrated and broader systems approach to prioritization and risk reduction for food-borne illness is needed. Further, consequences other than public health outcomes per se need to be taken into account. The caveat underlying this project and the proposed approach is that managers or decision makers actually desire to be explicit and transparent about their priorities and how important certain dimensions are compared to others.

The current work is a joint effort between researchers at the Public Health Agency of Canada, Health Canada, the University of Guelph and the University of Massachusetts to explore ways in which food-borne risks can be prioritized on the basis of a range of public health, economic and social factors. At the current time, various approaches have been developed for risk prioritization, although most are based on measures of health 
outcomes (for example, Quality Adjusted Life Years (QALYs), Disability Adjusted Life Years (DALYs) or Cost of Illness measures) and do not systematically account for other factors, for example importance to trade, consumer perceptions and the social sensitivity of the associated risks. In view of the multi-factorial nature of risk management decisions and the need to communicate such decisions among varied stakeholders, there is a need both to extend existing approaches and develop new methods for risk prioritization to include both health outcomes and other important factors. Hence, the aim of this report is to develop a Multi-Factorial Risk Prioritization Framework (MFRPF) for application to the risks associated with microbial hazards in food. This necessarily and rightly builds on existing efforts that attempt to develop risk management frameworks. The report provides a comprehensive conceptual paper that will form the basis of a wider process of consultation. Having defined a coherent methodological framework for multi-factorial risk prioritization of microbial hazards in food, the next step will be to validate this tool through trial applications, followed by development of a generic model amenable to a variety of different situations and scenarios.

As noted above, the focus of the risk prioritization approach adopted here is to present a broader and more integrated approach to choices in the mitigation of microbial foodborne risks. In addition to considering the public health consequences of such choices, the framework also explicitly looks at additional factors that are known to influence decision-making. This requires the co-ordination, and possibly the reconciliation and weighting of a range of factors in the risk prioritization process. Such processes of trading-off competing outcomes and objectives require a coherent approach that makes the nature of such decisions clear and transparent.

Figure 1 and the sections that follow put forward a methodological framework for the ranking and prioritization of risks associated with microbial hazards in foods; that is the basic structure of the MFRPF. Central to the proposed framework, and shown in the center of the figure, are four dimensions of risks that are applied in the overall prioritization of the associated risks to society, namely Public Health, Consumer Risk Perceptions and Acceptance, Market-Level Impacts, and Social Sensitivity. These four factors are considered of central importance to decision-making in more advanced science- and risk-based food safety systems. Clearly, this list can be extended and the framework presented below is amenable to further development in this respect.

The outer loop of Figure 1 is based on the process design of the generic risk assessment and management framework proposed by Health Canada (Health Canada, 2000). This basic structure is iterative in nature, reflecting that a process of ongoing evaluation is necessary for prioritization and risk-management decision-making. Thus, the effective ranking of food risks and implementation of risk mitigation strategies leads to a reduction in specific risks and hence necessitates a re-iteration of the prioritization process and risk ranking.

The framework's risk evaluation process, or risk prioritization chain, has four main phases: Risk Evaluation, Multi-Factorial Assessment, Risk Management, and Monitoring and Review. The inter-linkage of process flows is shown through the four risk factors 
placed in the centre of the risk prioritization framework. These are assigned to each step of the prioritization process, thus highlighting the integration of these factors throughout each appraisal phase. A multi-factorial ranking is the basis for making decisions on the need to conduct formal multi-factorial assessment processes. Such formal assessments generally require significant resources and the multi-factorial ranking provides the rationale for decisions to invest scarce resources on particular risks over others.

\section{Figure 1. Multi-Factorial Risk Prioritization Framework (MFRPF):}

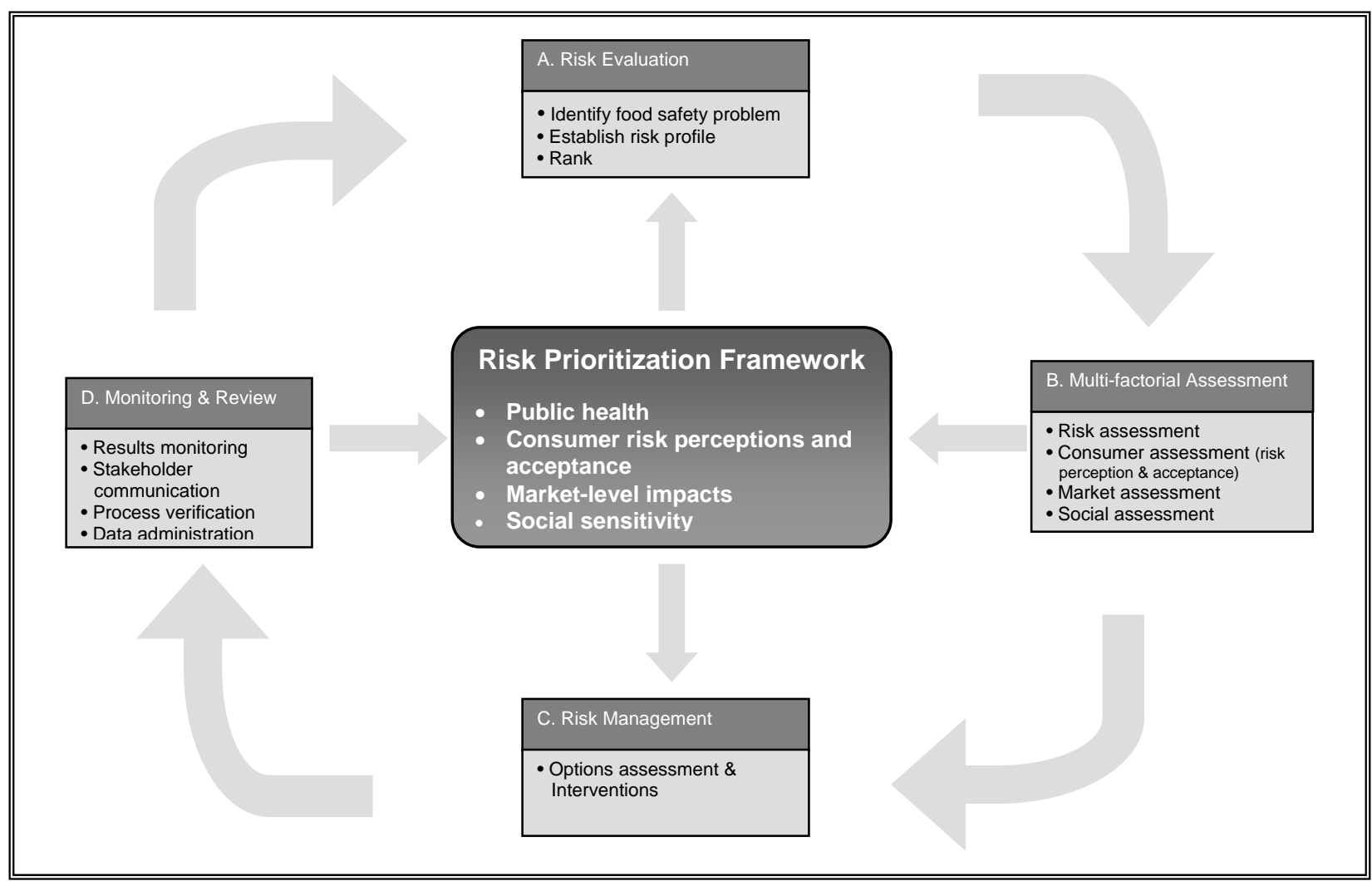

In the overall risk prioritization process, the individual steps are generally followed in a sequential order, beginning with Risk Evaluation [Block A]; this includes the identification of actual food safety risks and the current context for each risk. While some food-borne risks may already be well-defined, others can emerge abruptly revealing limited or a complete lack of information. It is recognised that there are potential challenges in developing a complete risk profile for each hazard within a given iteration. However, at a minimum, every risk would be ranked relative to other sources of hazard at this step. The proposed Risk Prioritization Framework includes both a knowledge base and tools to support the multi-factorial risk ranking. The purpose of the Risk Evaluation phase is to capture both the complexity of issues that different stakeholders may associate with a certain hazard and/or food as well as issues that arise from the four dimensions of risks.

The Multi-Factorial Assessment step [Block B] expands the formal scientific assessment procedures currently used to assess health risks to four areas: public health, consumer 
perceptions and acceptance, market-level impacts and social sensitivity. Although these assessments are integral components of the risk management framework, they are undertaken by experts with the required scientific and technical skills rather than risk managers. All available information from formal scientific assessment procedures is merged to generate detailed knowledge related to the four factors.

With respect to the assessment of hazard threats to public health factor, it is suggested that the procedure should closely follow the established joint WHO/FAO risk assessment guidelines that include: Hazard Identification; Hazard Characterization; Exposure Assessment; and Risk Characterization. An approach to the assessment of the consumer, economic and social factors related to food-borne risks is developed in this paper. The framework envisions the integration of discipline specific methods and techniques relevant to each of the prioritized factors. Based on scientific procedures a compilation of consumer risk perceptions and acceptance, market level impacts and social sensitivity will be conducted by experts. In some cases, however, it is recognized that new information and knowledge may need to be generated. The objective of this risk appraisal phase is to provide estimates of health risks, consumer perceptions, economic impacts, and social sensitivity that guide the subsequent Risk Management process [Block C] in the evaluation of options and interventions.

The Monitoring and Review of risk ranking and prioritized interventions [Block D] includes routine surveillance and data gathering designed to trace back and evaluate specific interventions. This information may also be used to update the knowledge base. The entire cycle is repeated at periodic intervals to re-evaluate priorities. However, the exemplary sequence and iterative structure outlined in this generic framework is primarily a logical and functional representation of the approach.

\section{Literature RevieW ANd Previous Work:}

In order to outline the need for a science- and system-based approach for risk prioritization, the following section reviews and evaluates different microbial risk prioritization and management frameworks that have been developed by governmental and regulatory institutions in a variety of countries. The review is intended to allow us to identify systematically the strengths and weaknesses of published risk prioritization frameworks.

To facilitate the comparison of existing risk prioritization frameworks, the review includes an evaluation of each framework's use of the four proposed dimensions: public health; market level impacts; consumer risk perceptions and acceptance; and social sensitivity of the risk incidence.

A number of attempts have been made to develop guiding principles for undertaking food-borne pathogen risk assessments and while these are not prioritization frameworks per se, these documents can still provide some guidance to the development of the MFRPF. Most notable is the approach promoted by FAO/WHO as outlined in the report Principles and Guidelines for Incorporating Microbiological Risk Assessment in the Development of Food Safety Standards and Related Texts (FAO/WHO, 2002) (Table 1). 
Note that in Table 1 and subsequent tables, we flag instances where previously developed frameworks do not address the four dimensions we focus on (that is public health, consumer risk perceptions and acceptance, market-level impacts and social sensitivity).

\section{Table 1. Evaluation of FAO/WHO Principles and Guidelines for Incorporating Microbiological Risk Assessment in the Development of Food Safety Standards and Related Texts:}

\begin{tabular}{|c|c|}
\hline \multicolumn{2}{|r|}{ Scope and Approach } \\
\hline Scope & $\begin{array}{l}\text { JEMRA (Joint FAO/WHO Meetings on Microbiological Risk Assessment) provides } \\
\text { scientific basis for risk management of Codex Alimentarius regulation; Develop food } \\
\text { standards to protect consumer health, fair food trade; Principles and guidelines for } \\
\text { microbial risk assessment in foods, water. }\end{array}$ \\
\hline Approach & $\begin{array}{l}\text { Prioritized dose-response model of particular commodity-pathogen combinations; } \\
\text { Threshold versus non-threshold mechanisms; Independent vs. synergistic action; } \\
\text { Microbial hazard identification, exposure assessment, hazard characterization, risk } \\
\text { characterization. }\end{array}$ \\
\hline \multicolumn{2}{|r|}{ Dimensions } \\
\hline Public Health & $\begin{array}{l}\text { Adverse health effects: clinical forms, duration of illness, severity (morbidity, } \\
\text { mortality, sequelae) physiopathology, epidemiological pattern, secondary } \\
\text { transmission, impairment of quality of life); Input for cost-benefit + cost-effectiveness } \\
\text { analysis (QALY, DALY). }\end{array}$ \\
\hline $\begin{array}{l}\text { Market Level } \\
\text { Impact }\end{array}$ & Consideration of economic burden; Facilitation of fair trade. \\
\hline $\begin{array}{l}\text { Consumer } \\
\text { Perception }\end{array}$ & Not Addressed \\
\hline Social Sensitivity & Not Addressed \\
\hline Conclusions & $\begin{array}{l}\text { Provision of risk assessment information and guidelines to FAO, WHO, Codex } \\
\text { member countries; Provision of practical framework, structural approach } \\
\text { characterization of hazards in full risk assessment or stand-alone process. }\end{array}$ \\
\hline
\end{tabular}

Efforts have also been made to develop more structured risk prioritization frameworks, on which our own platform aims to build. This review covers five recent approaches, the principle findings of which are summarized in Tables 2 to 6:

- The Food Safety Universe Database (FSUDB) developed by the Ontario Ministry of Agriculture, Food and Rural Affairs (OMAFRA) as a semi-quantitative risk assessment tool (OMAFRA, 2003). This is taken to be broadly representative of approaches to risk prioritization in Canada at the current time. 
Table 2. Evaluation of OMAFRA's Food Safety Universe Database:

\begin{tabular}{|l|l|}
\hline \multicolumn{2}{|c|}{ Scope and Approach } \\
\hline Scope & $\begin{array}{l}\text { Compilation of database (FSUDB) to obtain, analyze and understand consequences of } \\
\text { food safety information; Calculation and weighting of safety scores, sub scores, } \\
\text { handling risk probability, uncertainty. }\end{array}$ \\
\hline Approach & $\begin{array}{l}\text { Multi-dimensional microbial and chemical hazard/food combinations; Food-chain } \\
\text { model; Incl. sabotage and bio-terrorism; Safety score algorithm model. }\end{array}$ \\
\hline \multicolumn{1}{|c|}{ Dimensions of Risk Prioritization } \\
\hline Public Health & $\begin{array}{l}\text { Ranking of severity of public health impacts: mortality, hospitalization, treatment, lost } \\
\text { days, stats. Value of life, chronic health impacts. }\end{array}$ \\
\hline $\begin{array}{l}\text { Market Level } \\
\text { Impact }\end{array}$ & Not Addressed \\
\hline $\begin{array}{l}\text { Consumer } \\
\text { Perception }\end{array}$ & Not Addressed \\
\hline Social Sensitivity & Not Addressed \\
\hline Conclusions & Overall Scores and sub scores of pathogen/food combinations: total and per serving. \\
\hline
\end{tabular}

- Australia and New Zealand are jointly developing a scientific and microbial risk based prioritization framework for foods lead by the New Zealand Food Safety Authority (NZFSA). The review was based on the report Food Sector Risk Ranking and Prioritization Models: The Methods (NZFSA, 2006) and an earlier draft A Risk Management Framework for Food Safety (NZFSA, 2002) that outlines regulatory frameworks for food risk prioritization in New Zealand. This approach is serving as a major input for collective food safety measures taken by Food Standards Australia New Zealand and is taken to be broadly representative of risk prioritization frameworks within the region.

Table 3. Evaluation of Risk Management Framework for Food Safety in Australia/ New Zealand:

\begin{tabular}{|l|l|}
\hline \multicolumn{2}{|c|}{ Scope and Approach } \\
\hline Scope & $\begin{array}{l}\text { Management of risks of food-borne pathogens to human health in cost-effective, } \\
\text { mandatory supply chain system; Information and decision support for risk managers } \\
\text { in Australia and New Zealand. }\end{array}$ \\
\hline Approach & $\begin{array}{l}\text { Microbial pathogen - food combinations; Food-chain model; Risk ranking, general } \\
\text { categorization of food-hazard impacts; Matrix approach, numerical scoring; Stepwise } \\
\text { model: definition, categorization, identification of risk attributes; Compilation of risk } \\
\text { summary sheets; Risk ranking. }\end{array}$ \\
\hline \multicolumn{1}{|c|}{ Dimensions of Risk Prioritization } \\
\hline Public Health & $\begin{array}{l}\text { Ranking of severity of public health impacts by ICMSF (International Commission on } \\
\text { Microbiological Specifications for Foods) standard: mortality, hospitalization, } \\
\text { sequelae, severity in sub populations; Categorization of adverse health effects: } \\
\text { unlikely, likely, very likely. }\end{array}$ \\
\hline $\begin{array}{l}\text { Market Level } \\
\text { Impact }\end{array}$ & $\begin{array}{l}\text { Economic effects on import / export shares and ranks (\%) of trade commodities. } \\
\text { Pensumer }\end{array}$ \\
\hline Social Sensitivity & Not Addressed \\
\hline Conclusions & $\begin{array}{l}\text { Participative risk ranking exercise; Total disease incidence, non-profitable incidence, } \\
\text { total disease burden to food; Results and further issues; Risk communication through } \\
\text { internet, print channels, stakeholder meetings. }\end{array}$ \\
\hline
\end{tabular}


- In the United States, the Food Safety Research Consortium (FSRC) has presented a multi-disciplinary and computerized risk-ranking tool. Reference was made to the Consortium's publication Identifying the Most Significant Microbiological Foodborne Hazards to Public Health - A New Risk Ranking Model” (FSRC, 2004) The FSRC's approach presents a decision-making tool that quantifies and compares relative public health burdens to society emanating from a variety of food-borne pathogens.

Table 4. Review of Risk Prioritization Framework Developed by Food Safety Research Consortium in the United States:

\begin{tabular}{|c|c|}
\hline \multicolumn{2}{|r|}{ Scope and Approach } \\
\hline Scope & $\begin{array}{l}\text { Computerized risk ranking tool; Rank, compare relative public health effects of } \\
\text { specific food-borne hazards; Provide widely acceptable transparent, objective risk } \\
\text { rankings; Facilitate risk ranking globally. }\end{array}$ \\
\hline Approach & $\begin{array}{l}\text { Monte-Carlo model; Multidimensional pathogen/food combinations (28 foods); } \\
\text { Estimation of pathogen incidence. }\end{array}$ \\
\hline \multicolumn{2}{|r|}{ Dimensions of Risk Prioritization } \\
\hline Public Health & $\begin{array}{l}\text { Top- down approach of Public health impacts: number of illnesses, number of } \\
\text { hospitalizations, number of deaths; Likelihood of symptom-severity outcomes; } \\
\text { Bottom-up: Average risk associate with food consumption; Expert (science, policy) } \\
\text { judgement on health effects; Monetary valuation of statistics: values of life (QALY, } \\
\text { Quality of Well Being (QWB)); Cost-of-illness and willingness to pay measures. }\end{array}$ \\
\hline $\begin{array}{l}\text { Market Level } \\
\text { Impact }\end{array}$ & Not Addressed \\
\hline $\begin{array}{l}\text { Consumer } \\
\text { Perception }\end{array}$ & Not Addressed \\
\hline Social Sensitivity & Not Addressed \\
\hline Conclusions & $\begin{array}{l}\text { Ranking modules: Estimation of pathogen incidence; Monetary valuation of health } \\
\text { impacts; Valuation of food categories; Ranking of foods, pathogens, food/pathogen } \\
\text { combinations. }\end{array}$ \\
\hline
\end{tabular}

- A proposal for a joint microbial risk prioritization and management framework by the European Union was published in 2002 (European Commission, 2002) and incorporated into EU law through Regulation EC 178/2002 and further elaborated in Directives EC 99/2003 and 2160/2003. Similar to the FAO/WHO guidelines reviewed above, the EU approach as outlined in the report Risk Assessment of Foodborne Bacterial Pathogens: Quantitative Methodology Relevant for Human Exposure Assessment (European Commission, 2002) is intended to provide guidelines for the establishment of pan-national standards. In particular the guidelines are designed to guide the harmonization of risk prioritization and management strategies of EU Member States. The framework directly highlights E. coli and Campylobacter as the most important microbial food-borne threats in the EU. 
Table 5. Evaluation of European Commission Approach to Risk Prioritization:

\begin{tabular}{|l|l|}
\hline \multicolumn{3}{|c|}{ Scope and Approach } \\
\hline Scope & $\begin{array}{l}\text { "Quality-of-Life” food-borne risks assessment framework; Farm-to-Fork holistic } \\
\text { iterative approach balancing risks and benefits to express food safety. }\end{array}$ \\
\hline Approach & $\begin{array}{l}\text { Multi food/pathogen dimension (Salmonella and Campylobacter focus); Pre } \\
\text { assessment model specification (Food Safety Objective (FSO)); Margin-of-exposure } \\
\text { approach; Weight-of-evidence principle; Risk-benefit valuation; Quality-of-Life } \\
\text { parameters; Monitoring of public health decisions. }\end{array}$ \\
\hline \multicolumn{1}{|c|}{ Dimensions of Risk Prioritization } \\
\hline Public Health & $\begin{array}{l}\text { "Quality-of-Life” concept, precautionary principle: Adverse health effects; Health } \\
\text { promotional effects, Nutritional efficacy, Safety levels for pathogens; Occupational } \\
\text { health (farmers); Highest priority for human health protection. }\end{array}$ \\
\hline $\begin{array}{l}\text { Market Level } \\
\text { Impact }\end{array}$ & $\begin{array}{l}\text { Economic impact assessment implications; employment, trade impact (intra-EU, } \\
\text { international, imports); Fair trade issues; Product / commodity dimension; }\end{array}$ \\
\hline $\begin{array}{l}\text { Consumer } \\
\text { Perception }\end{array}$ & $\begin{array}{l}\text { Sustainability, animal welfare, Ethical issues; Consumer risk-benefit perceptions; } \\
\text { Social distribution of risks benefits; Population(s) at risk/benefit. }\end{array}$ \\
\hline Social Sensitivity & Not Addressed \\
\hline Conclusions & $\begin{array}{l}\text { Theoretical framework guidelines; Restriction on use, control measures, labelling; } \\
\text { Monitoring and impact assessment of: Human health, environment, ecology, } \\
\text { occupational health, animal welfare, sustainability, economy, consumer perception. }\end{array}$ \\
\hline
\end{tabular}

- Among non-governmental institutional approaches to risk prioritization, the most recent framework relevant for food risk analysis has been presented by the International Risk Governance Council (IRGC, 2005). The IRGC approach constitutes an integrated analytical framework for risk governance, which is intended to provide comprehensive management strategies at the global level. In contrast to the previous models, the risk governance approach aims at the integration of a variety of scientific, economic and cultural aspects of risk the management process and is not restricted to risks associated with pathogen/food combinations.

\section{Table 6. Evaluation of Risk Prioritization Approach Proposed by the International Risk Governance Council:}

\begin{tabular}{|l|l|}
\hline \multicolumn{2}{|c|}{ Scope and Approach } \\
\hline Scope & $\begin{array}{l}\text { Integrated analytical framework for risk governance, development of participative, } \\
\text { comprehensive assessment, management strategies at global level; Integration of } \\
\text { scientific, social, cultural aspects. }\end{array}$ \\
\hline Approach & $\begin{array}{l}\text { Non-dimensional, multi-hazard framework for risk governance; Stepwise procedure: } \\
\text { Pre-assessment, risk appraisal, tolerability-acceptability judgement, risk management; } \\
\text { Key function of communication. }\end{array}$ \\
\hline \multicolumn{2}{|c|}{ Dimensions of Risk Prioritization } \\
\hline Public Health & $\begin{array}{l}\text { Minimization of external side effects of risk management; Predefined public health } \\
\text { focus. }\end{array}$ \\
\hline $\begin{array}{l}\text { Market Level } \\
\text { Impact }\end{array}$ & $\begin{array}{l}\text { Notion of importance of economic implications of risk assessment; Integration of } \\
\text { industry stakeholder concerns. }\end{array}$ \\
\hline $\begin{array}{l}\text { Consumer } \\
\text { Perception }\end{array}$ & $\begin{array}{l}\text { Concern assessment of risk perceptions, social concerns, socio-economic impacts; } \\
\text { Inclusion of contextual aspects of overall risk analysis: structure, interplay of actors, } \\
\text { regulatory environment, social, political impact. }\end{array}$ \\
\hline Social Sensitivity & Not Addressed \\
\hline Conclusions & $\begin{array}{l}\text { Solution to politically realizable, ethically publicly acceptable risk governance; } \\
\text { Importance of risk benefit evaluation; Importance of risk-risk trade offs. }\end{array}$ \\
\hline
\end{tabular}


In addition to the documented efforts listed above, a number of Asian and Pacific countries including India, Japan and Malaysia have began to advance their national foodsafety systems with respect to the introduction of more efficient risk assessment and management tools to reduce the increasing threats of microbial food-borne hazards. Many of these endeavours are summarized in the proceedings of the Regional Conference on Food Safety for Asia and the Pacific (FAO/WHO 2004). However, none of the advances made by these countries represents a coherent and working risk prioritization framework and they are, therefore, excluded form this review.

Finally, the review also included selected approaches developed as part of scientific or academic research projects. A number of approaches in the literature provide valuable input and stimuli for new and enhanced ways of prioritizing food-borne risks. The framework proposed by Ross and Sumner (2002) is reported in Table 7 and the framework proposed by Fischer et al. (2005) is summarized in Table 8.

Table 7. Review of Ross and Summer (2002) 'Risk Ranger’ Food Safety Risk Assessment Tool:

\begin{tabular}{|l|l|}
\hline \multicolumn{2}{|c|}{ Scope and Approach } \\
\hline Scope & $\begin{array}{l}\text { Computerized spreadsheet risk-ranking model; Exploration of individual, global risk } \\
\text { reduction strategies. }\end{array}$ \\
\hline Approach & $\begin{array}{l}\text { Non specific, implicit pathogen - food combinations; Food pathway: pre-processing, } \\
\text { processing, preparation. }\end{array}$ \\
\hline \multicolumn{2}{|c|}{ Dimension of Risk Prioritization } \\
\hline Public Health & $\begin{array}{l}\text { Health effects: Hazard severity; Likelihood of adverse health effects by amount } \\
\text { consumed, frequency, size of population, exposure at subsequent stages; Probability, } \\
\text { severity of illness per level of consumption, per population and year. }\end{array}$ \\
\hline $\begin{array}{l}\text { Market Level } \\
\text { Impact }\end{array}$ & $\begin{array}{l}\text { Not Addressed } \\
\text { Ponsumer }\end{array}$ \\
\hline Social Sensitivity & Not Addressed Addressed \\
\hline Conclusions & $\begin{array}{l}\text { Calculation of probabilities, severities of health outcomes by qualitative and } \\
\text { numerical weighted statements in questionnaire. }\end{array}$ \\
\hline
\end{tabular}

In comparing the reviewed frameworks with the proposed four-tier categorization system none of the existing frameworks shows a high level of comprehensiveness. The majority of approaches prioritizes and ranks pathogen/food combinations according to their overall human health effects such as the number of illnesses or deaths. However, composite measures such as Quality Adjusted Life Years (QALYs) and Disability Adjusted Life Years (DALYs), as recommended by the guidelines of FAO and WHO, are widely neglected. Only the FSRC project in the US uses composite and monetary measures (notably QALYs, cost of illness and willingness to pay) to quantify the public health effects of hazards and rank the most efficient and effective intervention strategies to reduce adverse health effects. 
Table 8. Evaluation of Fisher et al. (2005) Proposed Trans-Disciplinary Risk Analysis Framework in the Domestic Environment:

\begin{tabular}{|l|l|}
\hline \multicolumn{2}{|c|}{ Scope and Approach } \\
\hline Scope & $\begin{array}{l}\text { Trans-disciplinary approach to risk analysis at consumption level; Scientific, } \\
\text { behavioural dimensions of human health risk from microbial food pathogens. }\end{array}$ \\
\hline Approach & $\begin{array}{l}\text { Non-dimensional dual approach of microbial risk assessment; Analysis of } \\
\text { consumption behaviour; Explore potential interventions to reduce adverse behaviour; } \\
\text { Promote risk communication. }\end{array}$ \\
\hline \multicolumn{1}{|c|}{ Dimension of Risk Prioritization } \\
\hline Public Health & $\begin{array}{l}\text { Consideration of individual risk perceptions of food-borne pathogens as basis for } \\
\text { effectiveness of public health interventions; Importance of individual consumption } \\
\text { pattern, risk perception. }\end{array}$ \\
\hline $\begin{array}{l}\text { Market Level } \\
\text { Impact }\end{array}$ & Not Addressed \\
\hline $\begin{array}{l}\text { Consumer } \\
\text { Perception }\end{array}$ & Susceptibility key factor to effective industry intervention strategies. \\
\hline Social Sensitivity & Not Addressed \\
\hline Conclusions & $\begin{array}{l}\text { Addresses behavioural and cognitive dimension of microbial risk perception of food } \\
\text { safety. }\end{array}$ \\
\hline
\end{tabular}

Beyond the FSRC framework, most other approaches aim at ranking human health effects at the individual as well as the aggregate societal level, although with no continuous measures of health outcomes. For instance, the Australia/New Zealand and OMAFRA approaches apply rankings of the severity of public health impacts. The "Quality of Life" approach pursued by the EU's Food Safety Authority is the sole framework to emphasize explicitly the need for precaution in prioritizing food risks and the positive aspects associated with public health, namely the nutritional benefits of improved microbial food safety and overall health promotional effects of increased risk communication. However, the majority of the reviewed frameworks discuss the importance of considering the impacts of microbial food-borne risks on vulnerable subgroups in society for effective risk management strategies. Thus, adverse health effects on children, pregnant women, elderly and other immuno-compromised groups are generally taken into consideration.

Broadly, the potential economic market-level effects are missing from the reviewed riskprioritization frameworks. While all of the institutional frameworks mention the role of economics in the management process, it is only the EU's "Quality of Life” approach which precisely addresses the economic implications of microbial risks. The EU's approach conducts a separate economic impact assessment, which includes measures of employment and trade impacts (at the intra-EU and international levels) as well as the implications of risk reduction interventions on fair trade issues at the commodity level. The IRGC risk governance approach also stresses the importance of economic factors in prioritization. The approach strongly focuses on the participation of industry stakeholders in the risk management process.

With the exception of the EU-approach, none of the frameworks accounts for the economic effects of pathogen/food combinations specific to industries or international trade. Although the FSRC (2004) risk ranking approach does estimate the economic costs of intervention strategies and provides Cost of Illness (COI) and Willingness to Pay 
(WTP) measures, such estimates are made at the aggregate level and not related back to specific foods or hazards. Looking beyond the broader risk prioritization frameworks reviewed above, the analysis of interventions for control of Campylobacteriosis by the Dutch Campylobacter Risk Management Assessment (CARMA) project includes estimation of the economic losses and costs of intervention of different microbial risk reduction strategies based on a disease-burden model (Havelaar, 2002).

In relation to consumer risk perception and acceptance, there is generally little consideration of risk perceptions and acceptability per se. In particular, none of the reviewed frameworks comes close to the trans-disciplinary perspectives on consumer risk perceptions of microbial risks proposed by Fischer et al. (2005).

The EU and IRGC approaches are alone in attempting to address the broader contextual aspects of prioritizing risks. Their framework includes issues of sustainability and societal concerns (for example related to animal welfare) that may be taken into consideration when designing possible risk intervention policies. Furthermore, the EU also highlights the importance of balancing consumer perceptions of risks and benefits with the social risk-benefit distribution plus the overall size of the population(s) at risk/benefit, as opposed to only the adverse effects of microbial food-borne hazards. The IRGC framework provides an elaborate discussion on the factors of risk perception and appraisal but is not specific to consumer perceptions of food-borne risks. Proposed future extensions of the joint Australian/New Zealand risk prioritization efforts also propose: “....economic / social research-based project into improving our understanding of consumer perceptions and attitudes towards different food risks.”

The fourth dimension in our framework for the prioritization of microbial food-borne risks relates to social sensitivity. The FAO/WHO guidelines for risk analysis and the EU microbial risk framework both consider social and ethical concerns in societies associated with regulatory interventions intended to lower the burden of microbial food- and waterborne hazards. This reflects perceptions that social and ethical concerns will become increasingly important in risk management decisions. Further, the EU in particular recognizes the need to consider the social impacts of its food safety controls beyond Europe and in particular on developing countries. Thus, Regulation EC178/2002 requires that Member States and the Commission: "give particular attention to the special development, financial and trade needs of developing countries, with a view to ensuring that international standards do not create unnecessary obstacles to exports from developing countries”.

In categorizing existing frameworks for risk prioritization and management of microbial food-borne hazards the review reveals important similarities and, perhaps more importantly, discrepancies between the various approaches being applied or developed globally. The majority of the reviewed frameworks feature a number of key factors directed at measurement of the public health effects of microbial hazards and associated interventions. However, we would argue that none of the existing approaches provides an adequate consideration of the entire range of factors that needs to be considered in prioritizing risks in the contemporary setting. For example, in many cases rather crude 
and discrete measures of health outcomes are employed that are not amenable to aggregation and economic measurement. Further, where an attempt is made at assessing the economic impacts of food-borne risks, the focus is typically narrow and at the aggregate level, rather than considering market-level effects at the industry level, wider macroeconomic impacts, etc. Little or no salience is given to impacts on consumer perceptions and acceptability of interventions; indeed differential impacts at the individual level are only considered to the extent that they are encapsulated in the definition of 'at risk' groups in terms of health outcomes. It is perhaps not surprising, therefore, that wider social considerations are given little or no consideration. Although, some of these issues have begun to attract the attention of researchers, risk managers and other stakeholders in the field of risk prioritization, there is a need to begin integrating such factors into the frameworks we employ. The approach outlined below attempts to do this.

\section{Multi-Factorial Risk Prioritization - Overview of the PROCESS:}

This section provides a brief overview of the MFRPF, followed by a more detailed description of the approach used to operationalize the framework we propose and methods that can be used to address the issue of aggregating the identified prioritization factors.

The review of existing risk prioritization frameworks provides a platform for the development of our multi-factorial risk prioritization platform. An immediate distinction between prior work and the framework proposed here is that the scope is widened from the sole focus on public health to other socio-economic dimensions. Ultimately, the aim of the framework is to facilitate and improve the decision-making of risk managers. Further, the approach we develop is meant to provide a tool that allows the level and accuracy of analysis to be proportionate to the complexity of a specific issue and to be employed as such at the discretion of the decision-maker. Consequently, the framework not only includes what could be termed as 'public health risk prioritization' but also highlights how risk-based rankings, and subsequently risk management decision-making, is affected when additional influencing factors are considered.

The methodological framework must be cognizant of the fact that food consumption, as well as food marketing and trade, carry benefits and risks that must be weighed and possibly reconciled in order to rank microbial hazards in foods. Central to the framework proposed in Figure 1 are the different classes of risks to society that are considered in the overall prioritization of microbial food-borne risks. Among the four factors, summarized in the centre of the framework, issues of human and public health are clearly considered to be critical in effective risk mitigation strategies and decision-making in the public interest. Of the remaining factors, consumer perceptions of risks associated with particular food/hazard combinations and their acceptance in every-day life are crucial to risk ranking and management decisions. Furthermore, market-level impacts of microbial hazards and preventive interventions to reduce accruing threats are crucial to the performance of food markets and to international trade. Also important are social, ethical and environmental sensitivities in society that may come along with selected risks and 
risk mitigation strategies and interventions. We note that the overall order of importance of the factors is not predetermined and largely depends on the decision maker's appraisal.

The proposed framework is based on the systematic organization and analysis of data on the multiple factors. The outline of this process is illustrated in Figure 2. The basic building block of the information structure is a three-dimensional cube based on pathogen-food-factor relationships shown in the upper right corner. Each cell of the cube has an information card associated with it as illustrated on the left side of Figure 2. Data from the cube can be aggregated along different dimensions. This figure illustrates one possible aggregation (across the four factors for $E$ coli 0157:H7 in beef) and one of several possible means of further presenting the aggregated information (a cobweb visualization). The basic structure of the framework is described below, with detailed description being presented in the next section. Overall, an important feature of this approach is that it generates useful information for risk management decision-making at all levels of implementation. Thus, decision-making capacity is enhanced by introducing different levels of analysis that enhance the decision-maker's ability to synthesize and aggregate risk factors.

Starting with the compilation of necessary information on the four risk factors, namely public health, consumer risk perception and acceptance, market-level impacts and social sensitivity, a system of data cards is used to organize the collection and storage of available information. It is important to note that the information contained in these cards is not pre-processed in any way or aggregated across factors. Rather, the cards are intended to enhance the way risk-oriented decisions are currently made by organizing existing information.

Typically, risk rankings are obtained by accounting for 'public health' criteria similar to those defined here. These criteria may be informed by diverse sources ranging from concrete statistics (for example DALYs) to "plausible assumptions" (for example "threat to vulnerable populations'). Consistency may be lacking in the way in which these criteria are typically considered in prioritizing microbial food-borne risks. The operationalization of the MFRPF for the public health factor may include available data on food-borne illness impact indicators (for example DALYs and QALYs) and estimates of economic indicators (for example COI). Similarly, the information cards for the other factors will include diverse information relevant to the particular factors. Here, marketlevel impacts will likely have the most extensive and diverse data set, for example using economic indicators on domestic markets and international trade from a variety of sources. Each information card, representing a pathogen-food-factor combination could carry a trend indicator suggesting whether it is increasing or decreasing in importance. 
Figure 2. Multi-Factorial Risk Prioritization - Process and Aggregation:

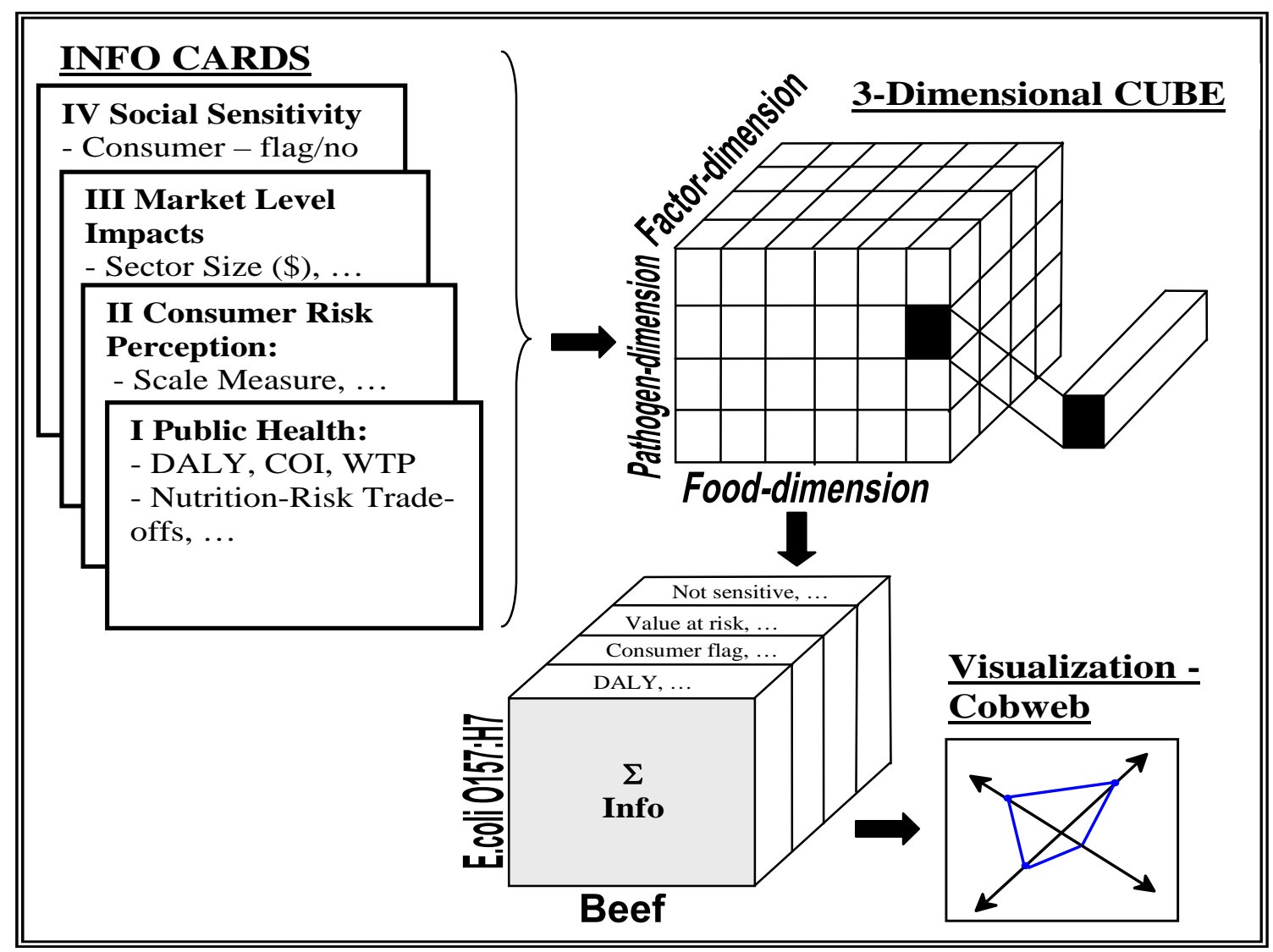

Because the basic organizational structure of the prioritization framework is the threedimensional cube shown in Figure 2, the development of information cards on specific pathogen-food-factor combinations is the minimum level of information for the process of prioritization. Since the data are not processed, this development provides a transparent starting point for further analysis. As a next stage, information can be aggregated in several ways. The construction of a CUBE-like structure provides a mechanism to aid the decision maker in considering and visualizing multiple approaches to the prioritization problem. Examples include comparisons of a pathogen's impact and severity levels across food products (y-axis) or the alternative analysis of the overall threat of microbial hazards affecting a single food category (x-axis). The aggregation step also facilitates the consistency of microbial risk data and identifies major gaps in the scientific risk analysis that impact the ability of decision-makers to effectively prioritize risks.

For example, the pathogen-food combination E. coli O157:H7-beef may be characterized by a DALY score as a key public health measure. Its magnitude would then be directly comparable to DALY scores assigned to other pathogen-food combinations in the CUBE structure. Consumer perception and acceptability of health risks from E. coli O157:H7 in meat products might be expressed using a consumer flag-quality scale measure from 'low' to 'high'. A measure of the total market value at risk is one possible aggregate 
measure of the associated market-level impacts. Social sensitivity issues might include concerns about the health threat of E. coli O157:H7 to vulnerable societal groups or the possibility that small beef producers could face challenges in complying with associated new regulations.

Based on the selection of risk measures, preliminary results for different pathogen-food combinations could be compared using various presentation formats. Possible approaches discussed in the next section include aggregate scores, out-ranking and cobwebs that visually show the dimensions of the factors for different pathogen-food pairings. For example, cobweb diagrams create a graphical profile of the food-borne risk factors associated with a pathogen-food pairing. They provide the decision-maker with a mechanism better to consider, visualize and compare the impacts of different pathogenfood combinations. In order to generate the diagrams, the impact along each factor must be translated into index scales. It is important to note that these scales do not have to be the same for each factor. However, the scales do need to be consistent across pathogen and product combinations. While our emphasis is on the product hazard dimension, it is important to note that results can also be presented for any one of the four prioritized factors.

The MFRPF approach is a basis for decision-making on the need to conduct formal multi-factorial assessments of microbial food-borne risks. Hence, the prioritization process will require significant input that provides the rationale for decisions to invest scarce resources on particular risks over others. In addition, the approach may be used as an input to the selection of priority pathogen-food combinations once more detailed information is collected. In both cases, effective and robust rankings of microbial foodborne risks will critically depend on the availability, comprehensiveness and quality of data from various scientific fields. In some cases, that data may not be readily available currently. Therefore, risk management decisions and evaluations of intervention strategies have to take into account the overall uncertainty associated with the data collection and analysis process used in the risk prioritization framework.

Another issue that arises in the prioritization of risks and associated evaluation of interventions is consideration of the apparent feasibility of alternative mitigation strategies. Previous approaches to the prioritization of food-borne risks have tended to conflate prioritization of specific microbial risks in foods with the availability of feasible mitigation strategies to address these risks. As a result, the prioritization exercise may begin to rank a pathogen-food pairing as a high priority based on its public health impact but then fail to rank it as a priority for action because feasible interventions are not evident. A second pathogen-food pairing with a similar risk profile may be ranked higher because easily identifiable and feasible interventions are associated. A third pathogenfood combination may have a lower risk profile but makes an action list because it is easy to address. The result is likely to be inconsistent risk ranking. To avoid this pitfall, the MFRPF treats feasibility analysis separately in the prioritization process.

Figure 3 expands on Figure 1 by considering uncertainty and feasibility in the iterative process of multi-factorial prioritization. As shown, a separate procedure addresses these 
issues. Within the iterative prioritization process, the first round of steps (risk evaluation, multi-factor risk assessment, risk management, and monitoring and review) is pursued to produce a ranking of microbial food-borne risks of (for example) different pathogen-food combinations. These results generate a 'List A' to which feasibility analysis for interventions and uncertainty assessments are applied. Overlaying these additional attributes on to 'List A' generates a weighted 'List B' based on feasibility analysis for further use in risk management actions by decision-makers. It also generates a 'List C' of pathogen-food risks where the degree of uncertainty of information makes prioritization difficult. These risks may be priorities for further generation of information.

Figure 3. Feasibility and Uncertainty in Multi-Factorial Risk Prioritization:

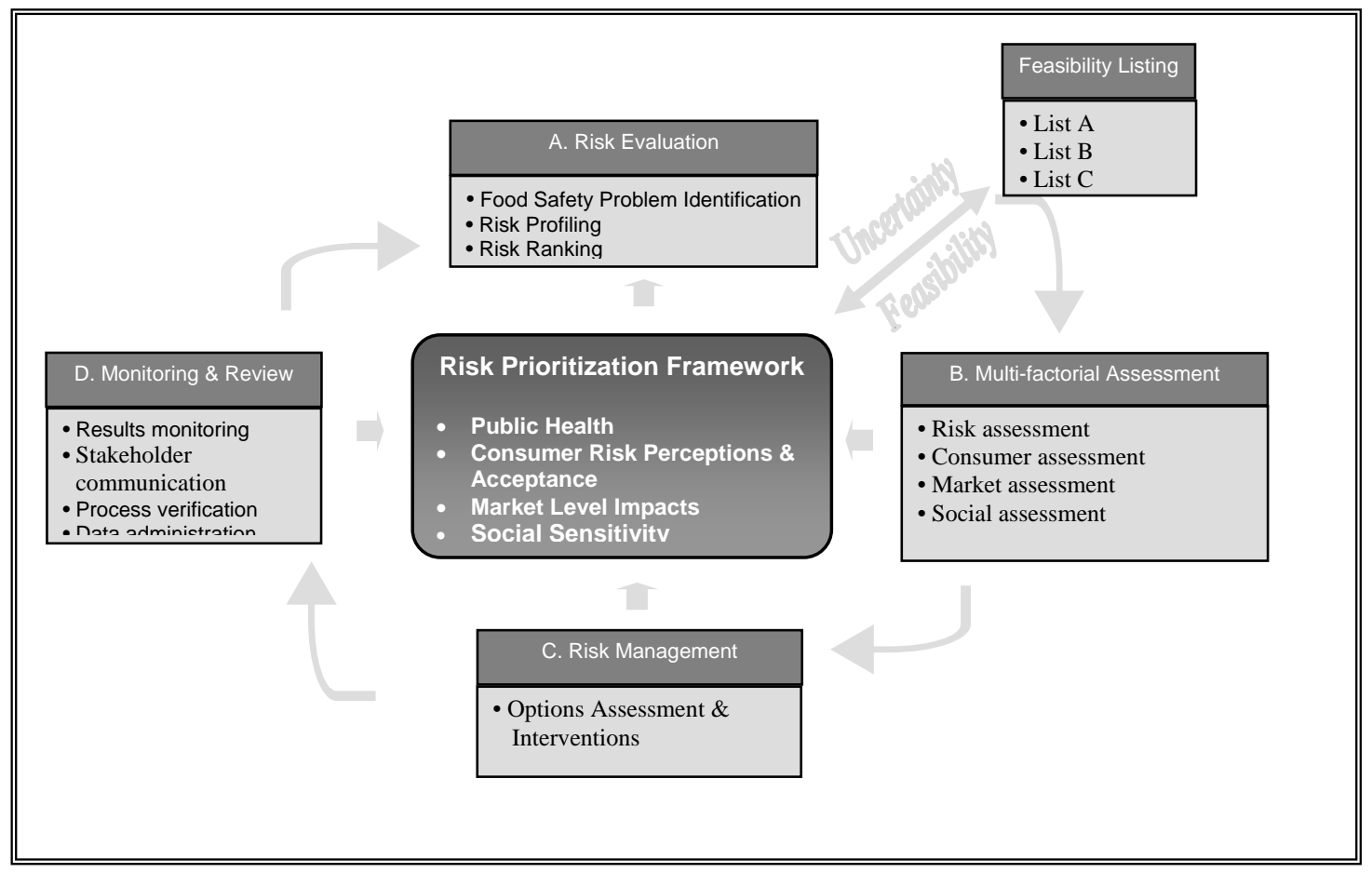

The separation of feasibility and uncertainty issues through the use of 'Lists A, B and C' allows risk managers to focus separately on distinct dimensions of the overall prioritization. 'List A' provides information for ranking without a consideration of the feasibility of interventions and given current information. 'List B' provides information more targeted to the setting of short term plans for adoption of immediate risk mitigation strategies. 'List C' allows the decision-maker to focus on pathogen-food combinations that are important to address in future science and technology development. Having all three lists available provides added information to decision-makers.

The greatest challenge in the application of the MFRPF is both combining and simultaneously presenting the ranking factors in ways that facilitate effective risk management decisions making. In this regard, we expect to develop a small range of presentation formats to test with decision-makers. 


\section{THE MEASUREMENT OF FACTORS:}

The Prioritization Framework is intended to incorporate the central concern of public health but also to include other important factors that may influence the priority given to different product/pathogen pairings, products and/or pathogens. We anticipate that in most cases each of the four ranking factors can be adequately represented by a small number of dimensions. Further research is needed to identify the representative dimensions. In most cases, factors are measured as levels, although they may also be measured as changes over time.

As has already been outlined, four broad attributes are used as inputs into the MFRPF. These attributes represent public health, consumer risk perceptions and acceptability, market-level impacts and social sensitivity. In turn, these four factors are the aggregates of a series of underlying issues and attributes, as outlined below. Before turning to these, however, issues related to the measurement of the attributes of each of these are discussed more generally.

\section{Measurement Issues:}

Given the range of presentation formats used in the framework, and the different means by which the various elements are represented, it is important to contextualize measurement of the different elements. Four broad metrics will be used: discrete variables, ordinal scales, counts and continuous measures.

A discrete measure takes a value of zero or one, typically with the value of one being used to indicate the presence of the attribute of interest. Discrete measures are sometimes referred to as indicator or dummy variables. As an example, an indicator variable may be used to show when a particular sub-group of the population is susceptible to a particular food-borne pathogen. Alternatively, an indicator variable could be used to indicate when an attribute or factor is a broad concern, when no other information is available (that is the indicator assumes a value of one to show presence of concern).

Sometimes, however, the amount of information that is available suggests levels of concern, awareness, etc. In these instances, one can represent the degree of an affect using ordinal scales. The idea here is to use a numerical scale to represent the order (or rank) of affect. Such an approach is often used in marketing research via multi-point Likert scales. These are used to allow survey respondents to indicate the level of agreement or disagreement with a statement or claim using an anchored and defined scale, such as:

$$
\begin{aligned}
& 1=\text { Strongly disagree } \\
& 2=\text { Disagree } \\
& 3=\text { Neutral } \\
& 4=\text { Agree } \\
& 5=\text { Strongly agree }
\end{aligned}
$$

The notion here is that the number assigned to a particular response reflects the ordering of some affect (such as strength of agreement or disagreement, level of interest, etc.). In 
assessing the impact of a particular food-borne pathogen on, say, export competitiveness, one might use the following scale:

$$
\begin{aligned}
& 1=\text { None } \\
& 2=\text { Slight } \\
& 3=\text { Moderate } \\
& 4=\text { Large } \\
& 5=\text { Very large }
\end{aligned}
$$

Ordered scales can also be used to impart categorical effects associated with the different factors. For example, information gathered in support of the framework may not enable precise measurement of the effect of a food-borne pathogen-related illness, but might reflect a broad category, such as:

$$
\begin{aligned}
& 1=\text { Low impact } \\
& 2=\text { Medium impact } \\
& 3=\text { High impact }
\end{aligned}
$$

While somewhat vague in terms of precise meaning, the advantage of such an approach is that it allows decision-makers to see the gradations of impact/effect/concern.

Count data can also serve a useful purpose in communicating information via the framework, and might include elements such as number of cases associated with a particular product-pathogen combination. Lastly, continuous measures can be used to capture measures such as value, volume, ratios and in some instances, index numbers.

Recognize that, in an attempt to make the framework easier to use, one might map either counts or continuous variables into ordinal scales. For example, rather than report the share of total production exported (an element of the market-level impact dimension), one might take this share's value and develop three levels, namely low, medium and high, as a means to simplify presentation of this information. Indeed, development of such categorical maps makes it much easier to aggregate across products and pathogens. Moreover, ordinal scales are used in other frameworks. For instance, the Ontario Ministry of Agriculture, Food and Rural Affairs uses a four-point ordinal scale (with values negligible, low, medium and high) to rate various elements/factors in their risk assessment framework (OMAFRA, 2003).

Each of the four factors in the risk prioritization framework is now described in turn.

\section{Public Health:}

To capture the broad impact of a food-borne pathogen-based disease incidence, the first attribute in the framework reflects health effects. To gauge the burden of an incidence, the public health attribute is composed of several elements. These include background information on the incidence and severity of the disease, as well as monetization of the impact of the pathogen. The incidence and severity measures will focus on: the number 
of illnesses, hospitalizations and deaths related to the food-borne pathogen, and a trend analysis of incidence, even if only to indicate an upward or downward tendency.

Inclusion of basic summary information of this kind is consistent with the FSRC's approach to prioritizing risk reduction opportunities in food-borne illnesses, as reviewed in Section II. However, the FSRC also incorporates additional measures reflecting the burden and cost of disease (that is DALY/QALY, COI, and WTP). Use of such measures is motivated by several factors, including:

- $\quad$ Ease of use when communicating the estimated impact to decision-makers.

- Amenable to aggregation, thus enable more detailed analysis relate to particular product-pathogen combinations.

- Ease of comparison with the economic benefits arising from risk reduction strategies.

- Provision of a complete ranking of expenditure activities (Kuchler and Golan, 1999), thus enabling more transparent comparison of the impacts associated with a given incidence.

For our purposes, we will include two additional measures of impact, namely DALYs and COI , both of which are discussed below.

\section{Disability Adjusted Life Years (DALYs):}

Disability Adjusted Life Years (DALYs) will be utilized, in addition to COI, for assessing public health impacts. Using both measures builds on existing methodologies (for example CARMA; see Mangen et al., (forthcoming)), and serves to account for different dimensions of public health. Both the DALY and COI approaches enable development of health indices associated with each food-pathogen combination. These indices could be treated either as a continuous scale (either in total or on a per incidence basis), or could be categorized (for example low, medium or high) based on experience with previous incidences. Information on the number of cases, hospitalizations and deaths arising from the illness/incidence would be useful in characterizing and categorizing these costs.

An important issue is the use of DALYs rather than Quality-Adjusted Life Years (QALYs). According to Gold et al. (2002), QALYs and DALYs are both population health measures of Health-Adjusted Life Years (HALYs) that permit measurement of morbidity and mortality. DALYs are considered to be a variant of QALYs, where QALYs measure the utility of being in a certain health state and DALYs measure the disutility of being in that same health state (Murray and Acharya, 1997). The QALY represents the fraction of one year in full health that makes the individual indifferent to spending one full year in a less than perfect health state. Hence, QALYs are usually between zero and one, where zero represents death, and one full health, and are assumed to represent the utility of being in a certain health state. DALYs, in contrast, incorporate age-weighting and measure disability on a scale of zero (perfect health) to one (death). According to Murray and Acharya (1997, p. 704), DALYs can be considered a 'negative' concept since they consider the loss of a healthy life year. Conversely, QALYs can be 
considered a 'positive' concept since they are analogous to a healthy life year. Both QALYs and DALYs may be used directly as measures of the impact of food-borne disease.

While QALYs are commonly used in health economics, they are applied less frequently in economic analysis of food safety. Including the DALY in the public health attribute enables account to be taken of the morbidity and mortality arising from illness (that is the DALY reflects consequences and severity). Moreover, the DALY can be applied to the population as a whole, as well as sub-populations, thus engendering a great deal of flexibility when calculating the impact of illness.

In practice, monetization of the DALY can be complicated since it represents the cumulative loss of years. In principle, one could use the value of a statistical life. However, consideration needs to be given to the point in a person's life at which the illness (or death) occurs; quite clearly, the value of a statistical life for a 21 year old is different than that of a 73 year old. In this respect, it should be noted that techniques through which a quality-adjusted value of life can be calculated exist (see for example Moore and Viscusi, 1988; Research Triangle Institute, 1988) that enable more meaningful calculation of the value of a DALY to be made. A further issue relates to attribution of illnesses to food versus other routes. Clear linkages must be established between the food-pathogen combinations and the incidence of illness, otherwise, calculation of DALYs related to one specific food-pathogen combination will be misleading. This latter issue suggests need for a great deal of data scrutinizing, development and on-going monitoring in order to refine the attribution of DALYs to specific food-pathogen combinations.

\section{Cost-of-Illness (COI):}

Two approaches have been used to measure the monetized impact of food-borne pathogens, namely cost-of-illness (COI) and willingness-to-pay (WTP). Table 9 summarizes the main strengths and weaknesses of these two approaches as discussed in Kuchler and Golan (1999).

While COI may not be a true measure of social welfare, it does measure the actual value of expenditures and foregone wages arising from the illness, as opposed to the hypothetical values from WTP. Moreover, the COI approach does not require assumptions on the structure of preferences when aggregating across the population (as needed with WTP). Arguably, COI is better suited to measuring impacts at a national level, while WTP is geared to measuring individual welfare. Given the strengths and weaknesses, and bearing in mind that the aim of this study is the prioritization of foodborne pathogen risks across the population, COI would appear to be the preferred approach in this context.

We temper the choice of COI by noting that its use can mask differential food-borne pathogen effects across different groups of people. Some of these groups may be socially sensitive, especially particular sub-groups of consumers. However, while other frameworks merely discuss socially vulnerable sub-groups, we do not; rather, we account 
for social susceptibility in a different and more transparent way, via the social sensitivity dimension. As such, concerns that COI mask effects within such groups are taken into consideration when ranking risks. On the other hand, there is the potential to doublecount the role of socially-vulnerable sub-groups, such that care needs to be exercised in constructing the aggregation framework. At the very least, the presence of sociallysusceptible sub-groups needs to be flagged in the framework.

Table 9. Strengths and Weaknesses of Cost-of-Illness and Willingness-to-Pay Measures:

\begin{tabular}{|c|c|c|}
\hline Approach & Strengths & Weaknesses \\
\hline Cost-of-illness & $\begin{array}{l}\text { Easy to implement and } \\
\text { interpret } \\
\text { - } \text { Reflects dollars spent and } \\
\text { foregone wages arising } \\
\text { from illness/premature } \\
\text { death } \\
\text { - Indicates direction and size } \\
\text { of economic flows }\end{array}$ & 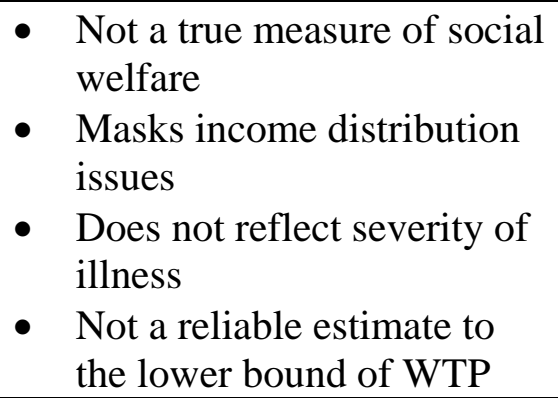 \\
\hline Willingness-to-pay & $\begin{array}{ll}\text { - } & \text { Reflects individual } \\
\text { - } & \text { A moferences and utility } \\
\text { of individual } \\
\text { valuation/welfare } \\
\text { - } \\
\text { More consistent with } \\
\text { applied welfare analysis } \\
\text { than COI }\end{array}$ & $\begin{array}{ll}\text { - } & \text { An ex ante measure and } \\
\text { subject to hypothetical bias } \\
\text { - } \\
\text { Does not reflect realized } \\
\text { value of damages } \\
\text { - } \quad \text { Requires stringent } \\
\text { aggregation assumption } \\
\text { - Large portion of variation } \\
\text { in WTP driven by income } \\
\text { differences rather than } \\
\text { preferences } \\
\text { - Sensitive to study } \\
\text { characteristics and difficult } \\
\text { to extrapolate across studies }\end{array}$ \\
\hline
\end{tabular}

Cost of illness reflects the medical and other costs arising from illness. The Economic Research Service (ERS) of the US Department of Agriculture (USDA) currently has a cost of illness calculator which can be used to determine these costs for five different pathogens (namely Salmonella, E. coli O157:H7, E. coli O157 STEC, Listeria and Campylobacter). The calculator is used to compute the cost arising from Salmonella and Shiga-toxin producing E. coli 0157:H7 (see <www.ers.usda.gov/data/foodborneillness >). The information used in the USDA calculator and particular costs associated with illnesses arising from these food-borne pathogens include: number of cases; distribution outcomes by severity level; medical care utilization; medical care costs; productivity costs; disutility costs and premature death. The dimensions of the cost of illness are discussed below to illustrate the data needs for such an analysis. 
The number of cases is a self-evident concept. The distribution of outcomes by severity level, however, is more complicated. In the ERS model, severity is categorized into four levels:

Severity 1: cases that do not visit a physician and recover fully.

Severity 2: cases that visit a physician and recover fully.

Severity 3: cases that are hospitalized and recover fully.

Severity 4: cases that visit a physician and/or are hospitalized and die.

Knowing the distribution of outcomes delineated by these severity levels is critically important, as this distribution is used when calculating total costs. The cost of illness associated with each severity level is first calculated (that is the cost per case times the number of cases at the severity level), and then the total cost of illness is determined by summing across severity levels.

Medical care utilization refers to the number of physician, emergency room, outpatient clinic and hospitalizations typically required with each severity level. The frequency of these visits is then used to calculate medical care costs based on per visit valuations associated with each type of visit. Per case medical costs at each severity level are then aggregated across the number of cases at that severity level and then across severity levels to determine total medial costs.

Productivity costs are calculated based on a valuation of time lost from work because of acute infectious illness. This element of costs is calculated only for those who are employed. ERS recognized an alternative assumption would reflect the productive costs associated with those outside the paid workforce, such as the unemployed, stay-at-home parents, children and the elderly. Regardless, productivity costs are calculated as the days lost from work at a wage per day wage rate. The former are determined based on national survey data. Wages per day are differentiated by the patient's age (to reflect differences in earnings at different points in their life) based on official wage data information, and adjusted to reflect severity level.

The two remaining cost estimates in the COI, disutility and premature death, reflect "pain and suffering" during illness and a willingness-to-pay to avoid death, respectively. While not identical, these two elements reflect valuation of the symptoms associated with the illness, and therefore, are broadly related to the concept of the DALY.

Currently, the ERS has applied the COI calculator to estimate the cost of illness associated with Salmonella (estimated at approximately US\$2.4 billion) and E. coli 0157:H7 (estimated at approximately US $\$ 430$ million). Clearly, these COI estimates by the ERS could serve as the basis for calculating cost of illness in the framework developed here. Indeed, a similar approach has recently been used by Henson to estimate the cost of poultry-borne Salmonella and Camploybacter in Ontario (Henson, 2006). One issue in this regard is the development of sufficiently detailed information to ascertain the cost of illness arising from incidence tied to specific food-pathogen combinations. ERS 
efforts have only focused the COI on specific pathogens; expanding their work to include a food dimension would certainly require considerable effort.

\section{Nutrition-Risk Trade-offs:}

One issue that DALY and COI calculations do not reflect is the nutritional benefits arising from consumption of foods that pose food-borne pathogen risks. It is generally agreed that most foods have nutritional value. However, most foods also carry a foodborne pathogen risk. The issue is whether, in the consumer's mind, the nutritional benefits offset the pathogen risk. An example of this is methylmercury warnings for some seafood. Methylmercury has negative health consequences for some consumers, while seafood in general can carry appreciable health benefits. The issue is whether the health benefits (and presumably associated economic benefits) from seafood consumption offset the possible deleterious effects of methylmercury ingestion. Likewise recent cases of E. coli 0157:H7 associated with spinach and other fresh green vegetables might dissuade consumers from eating such products, although their consumption is encouraged by health promoters as part of a healthy diet. Such net benefit offsets are currently beyond the scope of our framework. As one delves into the prioritization it will become more apparent how the net benefit offset needs to be dealt with, both from a specific (case-by-case) and general issue perspective. Net benefit offset is a concept that is difficult to quantify and incorporate (Institute of Medicine, In Press). This is an issue the study team (and others) are continuing to contemplate.

\section{Consumer Risk Perceptions and Acceptance:}

The potential for a net benefit offset arising from the consumption of some foods is indicative of a broader notion, namely consumer risk perception and risk acceptance. Consumers may well be willing to accept a food-borne pathogen risk if their perception of the risk is low or even if the perceived benefits arising from the consumption of that particular food offsets the perception of the ill consequences arising from a food-borne pathogen in a consumer's decision calculus. Indeed, consumer risk perceptions and acceptance is an important dimension in our framework, and one which reflects different factors.

Interventions may aim to address consumer concerns about food safety, aside from addressing the adverse health outcomes from food-borne hazards, and irrespective of the perceived or actual net benefit offsets arising from the nutritional content of the food. On the one hand, consumer risk perceptions can translate into shifts in market demand for particular food products; consumers may switch from products perceived to be 'less safe' to those perceived to be 'more safe', although such perceptions may bear only a loose relationship with the real risks to human health. On the other, consumer perceptions of the risks associated with food are an important determinant of the confidence the general public has in the security of the food system and in prevailing systems of public regulation and oversight. Relatively small, but highly visible, outbreaks of disease can have a profound impact on the trust that consumers have in food producers, manufacturers and/or distributors, or in government regulators. 
The large academic literature on risk acceptability, much of it outside of the arena of food but applicable in this context, indicates the importance of an individuals' perceptions of the quantitative risk to health and a range of other factors (NRC, 1996; Slovic, 2000). Perceptions of the risks associated with a particular pathogen-food combination, measured as the product of the probability of an adverse health outcome and the consequences should an adverse health outcome occur, may bear little relationship to any scientific determination of the risk (see for example Fischoff et al. 1978; Fife-Schaw and Rowe 1996; 2000; Frewer et al. 1998a). Risk perceptions among the lay public reflect the way in which risk contexts are framed, bias related to the ability to mentally visualise an adverse health outcome occurring, over-confidence in their own ability to assess risk, a tendency to discount very small risks, etc. Further, acceptability of a particular risk takes account of a wide range of qualitative factors that do not enter scientific risk assessment including the degree to which the risk is perceived to be controllable, whether exposure is voluntary or involuntary, the nature of the associated health outcomes over time (in particular whether they are acute or chronic), perceptions of the individual's and experts' knowledge of the risk, etc (see for example Fischoff et al., 1979; Slovic et al., 1980; Frewer et al., 1998a). On the one hand, the complexity and multi-dimensional nature of consumer risk perceptions makes it difficult to incorporate this element into the risk prioritization framework. On the other, however, existing literature does highlight the key factors that need to be taken into account when assessing the acceptability of the risk associated with a particular pathogen-risk combination, as described below.

To include a risk acceptability dimension in the risk prioritization framework a number of key factors need to be incorporated, most of which will be measured on Likert-type scales from 'low' to high'. Possible factors, with an indication of their hypothesized relationship to risk acceptability, are as follows:

- Perception of risk of an adverse health outcome (-)

- Degree to which risk is perceived to be controllable by the individual consumer $(+)$

- Degree to which risk is perceived to be controllable by regulators $(+)$

- Degree to which risk is perceived to be known to the individual $(+)$

- Degree to which risk is perceived to be known to scientists (+)

- Degree to which exposure to the risk is perceived to be voluntary $(+)$

- Degree to which the risk is perceived to be a natural phenomenon $(+)$

- Degree to which exposure to the risk is also perceived to yield benefits $(+)$

Measurement of risk acceptability and perception is complex. There is a considerable literature and survey-based research on how consumers rank different risks (see for example, Fife-Schaw and Rowe 1996, 2000; Fischoff et al. 1978; Frewer et al. 1994, 1997, 1998a; 1998b). However, as Frewer et al. (1998a) point out, food is not something which can be avoided. Thus, consumers may view food-related risks differently from avoidable risks. As such, the methods utilized to assess and understand food-risk perceptions are critically important. To this end, Frewer et al. (1998a) recommend a multi-stage approach to measure risk perceptions based on semi-structured interviews, various quantitative techniques and repertory grid analysis. 
In Frewer et al's (1998a) approach, respondents rank various hazards according to level of concern. Ranked hazards are then analyzed by the researcher to categorize and develop constructs defining the respondent's concerns. A unique, individualized questionnaire is then developed for that respondent, who assesses each hazard against the particular constructs included in their questionnaire. Generalized Procrusties analysis (GPA) (Gower, 1975; Gower and Dijksterhuis, 1990; Dijksterhuis and Gower, 1991) is then used to assess the results from the individualized questionnaires ${ }^{1}$, and broad based conclusions drawn.

This approach has been used in various settings (see, for example, Frewer et al. 1998a, 1998b; Henson et al. 2006). Following on from Frewer et al. (1998b) and Henson et al. (2006), consumer perceptions with respect to each of the factors listed above, and for particular pathogen-food combinations, would be derived through a consumer survey, using this bank of factors as a multi-item scale for measuring risk acceptability. Aggregation of the scores, assuming equal weighting across the factors, would then provide a single measure of risk acceptability. A single-item scale on the acceptability of the risk could also be included in order to permit validity of the scale to be assessed. Alternatively, a Delphi approach could be employed with a panel of experts on consumer risk perceptions, whereby scores are attached to the scales for particular pathogen-food combinations on the basis of predictions informed by the risk perception literature. A more pragmatic approach would to use crude proxies to capture risk perception and acceptability until such time that more detailed information becomes available based on further research.

\section{Market-Level Impacts:}

In addition to the human element associated with food-borne pathogen incidence, the impact of prominent outbreaks of disease in the past underscores the importance of understanding and quantifying how industry performance (see for example, Henson and Mazzocchi, 2002; Sparling and Caswell, 2006) is affected by food-borne pathogen incidents, broadly reflecting market-level effects. Such quantification applies not only to cases where an entire industry is affected (for example BSE in Europe, Canada and the US), but also when a single (or group) of firms is affected by an outbreak (such as E coli 0157:H7 outbreaks at individual food service or food manufacturing establishments with concomitant spill-over effects). The economic losses arising from a food-borne pathogen incidence can be large. A priori, it would then be prudent to understand better the expected economic impacts arising at an industry level from a specific food-pathogen based incidence.

In turn, the size and composition of potential economic losses depend on the likelihood of an incidence and the economic losses arising from that incidence. The former is often viewed as a rare event, and therefore very difficult to predict. However, unlike the COI calculation, this is not a matter of estimating the number of cases. Indeed, one incidence can be devastating for an industry (for example BSE in Canada). In this respect,

\footnotetext{
${ }^{1}$ GPA is an analytical technique which enables comparison of responses across scales which may differ across observations, as the case with individualized and tailored survey questionnaires.
} 
understanding the chance of an incidence, perhaps developed using a qualitative scale or based on a Delphi survey, would provide the information needed to internalize this likelihood in a decision making/prioritization framework.

In terms of defining the scope of the market, note that since countries are importers and exporters of food and agricultural products, the trade dimension cannot be ignored. In fact, market-level impacts need to be assessed with both domestic and international markets in mind. Moreover, the food processing sector, broadly speaking, is a significant economic entity. As such, the role of agri-food supply chains must also be reflected in the market-level impacts dimension. For our purposes, the supply chain will be delineated into three levels: the retail, process-distribution-wholesale and farm levels.

To help illustrate market-level impacts, and to summarize the relevant information, a market impact matrix could be developed. Table 10 illustrates the form such a matrix might take. Depending on the market of interest, economic importance can be captured using a variety of measures. We differentiate between domestic and international markets to help underscore the potential for a differential effect across these markets. In the domestic market, key measures would include: value of sales, volume of sales, and employment and wages at different points along the respective supply chains. Changes in consumption in the domestic and international market are also important barometers of industry performance changes arising from an incidence. Moreover, these changes are not limited to retail level changes only. Indeed, changes in demand for intermediate and farm level goods may also figure importantly into any analysis. In fact, the susceptibility of domestic and international demand to the incidence is of critical importance as an effect at the retail market will be felt throughout the supply chain.

With respect to export market impacts, one lesson from the BSE situation in Canada is the critical importance of understanding how decision-makers in export markets respond to the threat of a food-borne pathogen/threat. In this respect, it is vital to understand how a pathogen's impact on market access (for example: does the border remain open? what level of access is allowed?) and export competitiveness (for example how do consumers in export markets react?) will affect industry performance.

Various pieces of market intelligence would also serve to inform the assessment of industry performance. Other measures of export market impacts are also important in assessing industry performance changes arising from an incidence, such as:

- Share of value of trade in that commodity worldwide.

- Number of countries traded with.

- Concentration of trade with other countries (i.e. a trade concentration ratio).

- Volume of trade.

- Value of exports as a percent of value of domestic production.

By the same token, measures of import impacts arising from an incidence would aid in this analysis, such as vulnerability of the market to outbreaks, spill-over of reputation and percent of product that is imported. 
Table 10. Market Impacts Matrix with Suggested Elements:

\begin{tabular}{|c|c|c|}
\hline Sub-Sector & Domestic Market & International market \\
\hline Retail level & $\begin{array}{ll}- & \text { Value of sales (\$) } \\
\text { - } & \text { Volume of sales (\#) } \\
\text { - } & \text { Employment (\#) } \\
\text { - } & \text { Wages (\$) } \\
\text { - } & \text { Change in consumption (\%) }\end{array}$ & 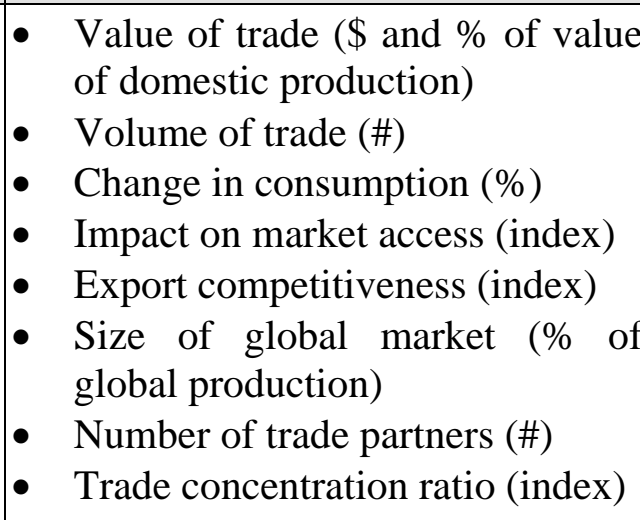 \\
\hline $\begin{array}{c}\text { Processing- } \\
\text { distributing- } \\
\text { wholesaling level }\end{array}$ & $\begin{array}{ll} & \text { Value of sales (\$) } \\
\text { - } & \text { Volume of sales (\#) } \\
\text { - } & \text { Employment (\#) } \\
\text { - } & \text { Wages (\$) } \\
\text { - } & \text { Change in consumption (\%) }\end{array}$ & 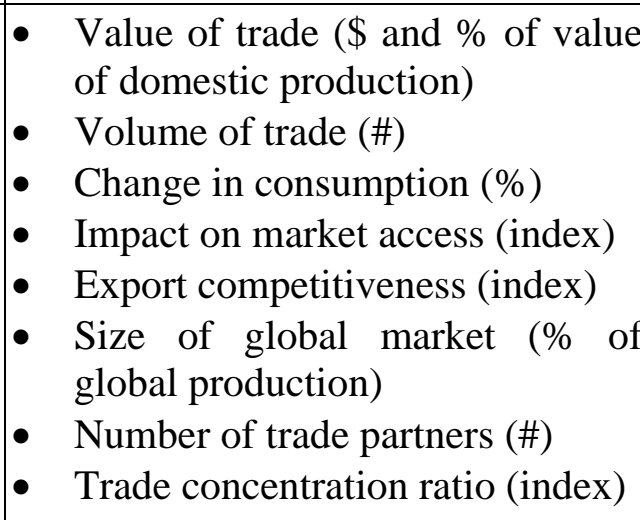 \\
\hline Farm level & $\begin{array}{ll}- & \text { Value of sales (\$) } \\
\text { - } & \text { Volume of sales (\#) } \\
\text { - } & \text { Employment (\#) } \\
\text { - } & \text { Wages (\$) } \\
\text { - } & \text { Change in consumption (\%) }\end{array}$ & $\begin{array}{ll}\text { - } & \text { Value of trade (\$ and \% of value } \\
\text { of domestic production) } \\
\text { - } & \text { Volume of trade (\#) } \\
\text { - } & \text { Change in consumption (\%) } \\
\text { - } & \text { Impact on market access (index) } \\
\text { - } & \text { Export competitiveness (index) } \\
\text { gize global market (\% of production) } \\
\text { - Number of trade partners (\#) } \\
\text { - Trade concentration ratio (index) }\end{array}$ \\
\hline
\end{tabular}

As with the public health attribute, industry performance, as characterized via expected economic loss, could be included in the framework as a continuous (that is dollar loss) or categorical variable (that is low, medium or high loss). To impart the dimensions and elements of this market impacts factor, Table 10 provides the market impact matrix, associated elements and the proposed means of measuring the different elements.

Coupled with information on the risk of an incident, information in the above table will enable calculation of the economic value at risk. The latter would take the form of an 
expected loss arising from a food-pathogen incident either in the domestic or international supply chains, or both. Moreover, to reflect better that an incident may not affect the full economic value of a market/industry, a Delphi survey could be undertaken to develop impact factors/multipliers for different food-pathogen combinations, and which reflect the scope of impact in terms of economic value at risk.

\section{Social Sensitivity:}

Apart from the aggregate risk to human health and the associated economic costs, the acceptability of risk to consumers and economic impact on the supply chain, interventions are driven by the potential impact on vulnerable groups whereby a greater weight is put on these impacts than on the 'average' for society as a whole. Further, society may be interested in the wider social consequences associated with food-borne illness, perhaps representing externalities that spread beyond food consumers and food markets. Finally, as with consumers, there may be vulnerable firms or other economic entities, for example because of size or precarious economic circumstances.

With respect to 'vulnerable' consumers, sensitivity to the adverse health effects for particular groups needs to be incorporated, namely:

- Infants and young children.

- Elderly.

- Low-income consumers.

- Aboriginal groups.

- Individuals with compromised immune-systems.

The sensitivity of impacts on these particular groups does not relate to the potentially greater risk that they may face from a particular pathogen-risk combination, which is incorporated into the public health dimension discussed above. Rather, the issue at hand here is the disproportionate or excess impact on these groups in terms of economic or welfare consequences and the fact that society as a whole has a tendency to be especially sensitive to the adverse impacts that groups such as these may incur. In turn, such concerns relate to, for example, their more limited ability to take averting actions to selfprotect, or because of altruism.

On the supply-side, vulnerable groups may include:

- Small producers.

- Small and medium-sized enterprises (SMEs).

- Enterprises in marginal economic and/or aboriginal areas.

- Enterprises representing disproportionately important sources of employment or livelihood.

Similarly, such concerns do not reflect the economic impact on such groups per se, but sensitivity to their greater vulnerability to the economic costs associated with the adverse health effects of a particular food-pathogen combination, the role such groups play in 
marginal rural areas or within the economies of economically-vulnerable areas, their contribution to the historical and/or social fabric of society, etc.

Finally, a range of wider ethical and social interests may be affected by the risks associated with a food-borne disease resulting from a particular pathogen-food combination and that should be incorporated into the framework. Examples include:

- Environment.

- Animal welfare.

- Ethical and religious beliefs.

- First nations’ rights.

These are perhaps more controversial in that they are dependent upon individual views and ethical positions, and there is far from consensus on even the relevance of such issues in a risk-prioritization context internationally.

To incorporate the potential social sensitivity impact of adverse health effects from a particular pathogen-food combination, Likert-type scales can be employed to reflect the vulnerability of the identified groups from 'low' to 'high'. Given the diversity of sensitive sub-groups within the consumer and firm/market groups, different scales should be used for each sub-group. These sub-group specific scales would be best elicited through a Delphi panel of informed experts on the health and/or economic impacts of food-borne risks. The scores for the individual vulnerable sub-groups could be incorporated into the framework as individual items or aggregated to derive a single social sensitivity measure. Recognize, of course, that aggregating across the individual vulnerable sub-groups assumes each is of equal concern unless a schedule of aggregation weights is employed. Also recognize that the public health dimension (that is COI and DALYs) incorporates and values the health effect on different sub-populations.

\section{Aggregation AND OPERATIONALIZATION OF THE FrAMEWORK:}

To reiterate, the MFRPF posits four dimensions to be considered in the prioritization of microbial food safety hazards, namely public health, consumer risk perceptions and acceptance, market-level impacts and social sensitivity. The motivation for including these criteria, and the various values that they encompass, has been rooted in the recognition that these factors play a central role in decision-making processes, whether or not the decision-maker explicitly defines and transparently processes them.

Ultimately, the aim of the framework is to improve the decision-making process by providing the tools necessary to allow these multiple criteria to be handled in a more rigorous manner. In addition to promoting a more complete, balanced and transparent decision-making process, the framework aims to provide the tools that allow the level of analysis to be proportionate to the complexity of the specific issue at hand and with the flexibility for different levels of analysis and detail to be employed at the discretion of the decision-maker. This section provides an overview of the framework's structure, describes the approaches used to operationalize the framework, and posits methods to address the issue of aggregating the various risk prioritization factors. 
Before proceeding to the implementation of the framework it is important to recognize from the outset the potentially quite formidable problems that may be faced in attempting to derive measures for the four prioritization factors. Largely, these relate to the paucity of available data and inherent difficulties in obtaining it.

- A key issue for the MFPRF is the ability to attribute cases of human disease across products and pathogens. This is critical both in deriving measures for the four factors for each food-pathogen combination and also to avoid double-counting in deriving measures across foods and/or pathogens. In many cases the data here are weak and often risk managers have to resort to expert opinions, perhaps derived using a structured instrument such as the Delphi survey. Several groups, including the FSRC, are working to improve food attribution methods (Batz et al. 2005).

- It can be extremely difficult to obtain reliable estimates of the full economic costs associated with food-borne illness, both due to data gaps and social sensitivity regarding the attachment of economic values to certain outcomes. Thus, in many calculations the value of non-market employment is excluded. There is also controversy over the appropriate valuation of human life; this is critical given that the value of premature mortality tends to dwarf other elements of the cost calculation.

- While existing research provides a 'snap shot' of the current state of consumer perceptions and acceptance of the risks associated with food-borne pathogens, it is evident that attitudes can change rapidly. Thus, there is a risk that basing the framework measures on historical data could significantly distort the nature and level of consumer concerns at a particular point in time. Further, while we might have a good notion of the nature of consumer perceptions of the risks associated with food per se, we have very little information on how they regard the risks associated with particular risk-pathogen combinations. Indeed, it may be very difficult to disaggregate and attribute consumer concerns to separable hazards.

At the same time, the framework has been developed in such a manner that the inherent uncertainties associated with specific elements of the framework are apparent. Indeed, it is strongly recommended that the prioritization of food-pathogen combinations produced by the framework are 'flagged' with the associated data uncertainties in order to act as a 'warning' to risk managers.

The framework is operationalized in three stages as outlined in Figure 4. These stages are the development of information cards, presentation of graphical profiles of risks using cobweb diagrams and formal analysis and integration of information using Multiple Criteria Decision Analysis. Each stage adds another dimension to decision-making capacity. This increased capacity is achieved by introducing different levels of analysis that enhance the decision-maker's ability to synthesize and aggregate the four risk prioritization factors. The first stage, developing information cards, could be considered the basic building blocks from which the prioritization process can begin. They also represent the minimum in our opinion, in terms of level of information, upon which a 
prioritization decision can be made across products and pathogens and be considered to be transparent and defensible.

Figure 4. Summary of Three Stages in Operationalizing and Aggregating the Framework:

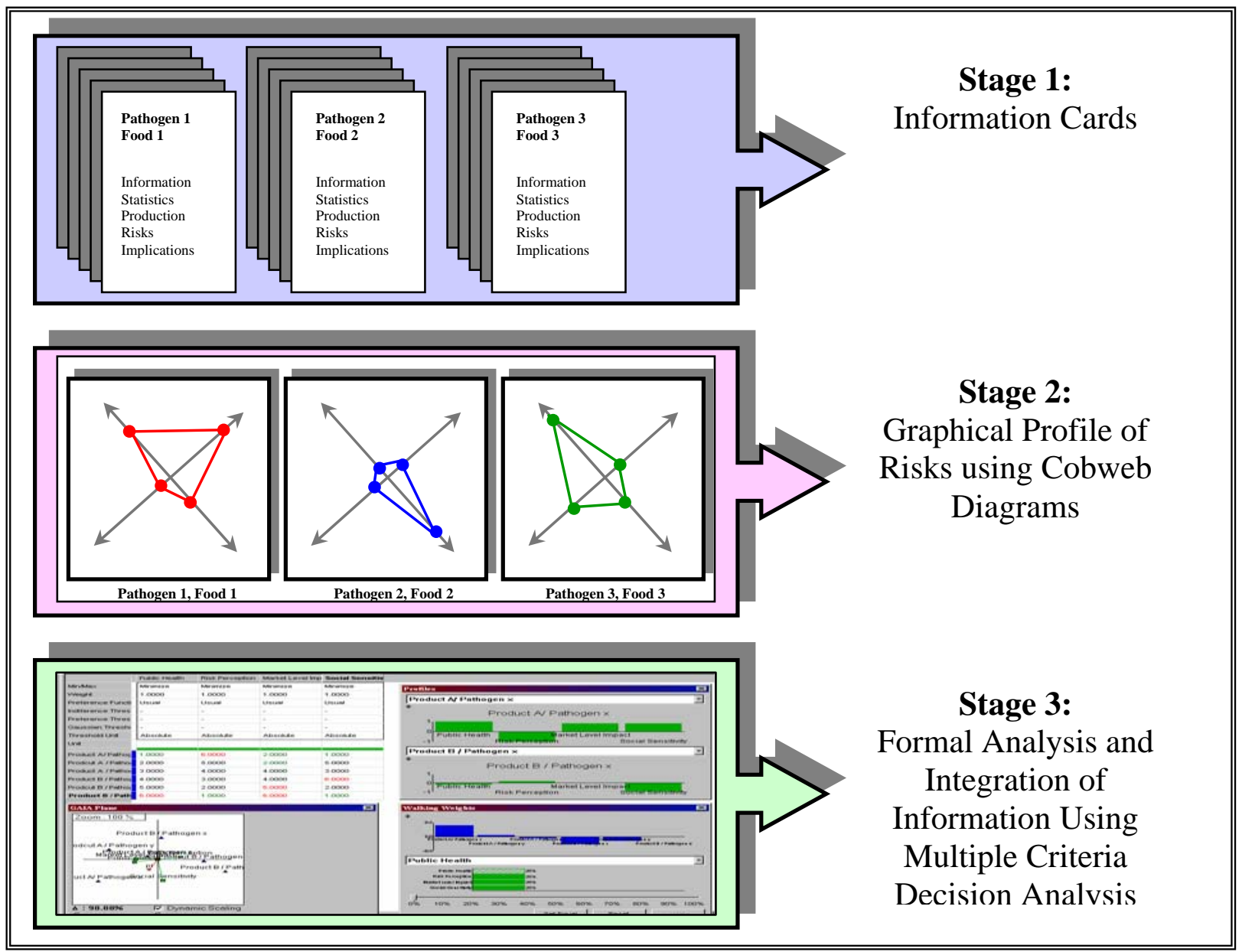

The information card for a product and pathogen combination summarizes relevant details for each of the prioritization factors. It is important to reiterate that the information provided by the cards is not pre-processed in any way, or aggregated across criteria for instance, but rather is intended simply to enhance the way decisions are made. Typically, decisions are made by taking account of similar criteria to those defined here, although these criteria are typically informed by diverse sources ranging from concrete statistics (for example public health measures) to "gut instinct" (for example social sensitivity). As a result, consistency may be lacking in the way in which these criteria are typically considered in a decision. The cards put information related to each criterion in one place and on a "level playing field", striving to increase consistency in how each is internalized and considered by decision makers.

Moving from Stage One to Stage Two requires that the information on the various information cards is mapped on to the cobweb diagrams. In fact, this is critical in order to operationalize the framework and be able to compare and prioritize different food- 
pathogen combinations. The translation of the data provided by the information cards into a cobweb diagram is intended to create a graphical profile of the food-pathogen combination's performance with respect to each of the risk prioritization factors. In turn, this provides a mechanism to consider, visualize and better compare the impact of different food-pathogen combinations across the factors.

The metrics used to measure the elements within each of the four prioritization factors, and summarized on the information cards, need to be combined to facilitate development of the cobweb diagrams. It is important to note that the scales used to quantify each of the four prioritization factors, as well as the multiple attribute scales that make up these factors, do not necessarily have to be the same. At the same time, the use of differing scales can, at least at first sight, create problems. For instance, combining a monetary value (such as the value of sales), with an ordered scale results in an unintuitive measure for that dimension.

As such, the continuous and count data contained in the information cards will be mapped into ordinal scales which impart the categorical magnitude of the respective element. The resulting score for each dimension can then be used to develop the cobweb diagram and then be incorporated into a Stage 3 analysis of the different food-pathogen combinations being considered. For instance, public health could be measured using DALYs or a number of cases of illness scale while social sensitivity and/or risk perception are each measured in entirely different ways. Where the scales must be consistent, however, is across pathogen and food combinations. Thus, for instance foodpathogen combination A must have a DALY score assigned to it, that is directly comparable to the DALY score assigned to food-pathogen combination B.

Scope also exists to focus attention on a food comparison. For instance, one may be interested in prioritizing different foods based on the totality of food-borne pathogen risks they represent. In this instance, one would be interested in scores for each factor for the product under question. For each product one would add up the respective factor scores across pathogens to get an overall score for that factor and that product. Having completed this for each product under question, cobweb diagrams can be developed and used to compare products. The output could then be used, in turn, as input to Stage Three.

By the same token, one might be interested in prioritizing pathogens by aggregating across foods. For each factor, one would add up the food-pathogen scores across foods in order to obtain a pathogen-specific score for that factor. These pathogen-specific scores could then be used to develop cobweb diagrams for each pathogen of interest and relevant comparisons made. As above, the output could then be used, in turn, as input to Stage Three.

Caution must be exercised when developing food or pathogen-specific scores and in utilizing these. In particular, not all pathogens affect all foods. Because of this, one would not aggregate across the universe of foods, nor pathogens. Moreover, food and pathogen-specific scores should also be normalized to reflect the number of pathogens or 
products that were aggregated over. Otherwise, scores for some foods (pathogens) may reflect a different set of pathogens (foods) which were aggregated.

A further complication in aggregating across pathogens and/or foods is the scope for double-counting. For instance, some economic information may be common across different pathogens for one product. At the same time, while some of the attributes underlying the four risk prioritization factors are common for a pathogen or product, others are unique (for example BSE in beef resulted in a border closure, while $E$ coli O157:H7 in beef would not have such an outcome). In order to aid interpretation of the results, we need to flag which of these attributes is common and what is different across pathogens and/or foods. Equally, it is important to highlight the dominant factors pushing a particular issue up or down the priority list, to assist decision-makers in applying the results.

In comparing the cobweb diagram for each food-pathogen combination, decision-makers can assess, without expressly defining it, how much value they place on each criterion, in a manner similar to how decisions are likely to be taken currently, and arrive at a ranking of food-pathogen combinations. The cobweb diagrams could consist of four dimensions - one each for public health, consumer risk perceptions and acceptance, market-level impacts and social sensitivity - in which case the multiple elements that make up each of these prioritization factors represents a ratio or summary score of the constituent multiple components. Alternatively, these multiple attributes could themselves be included in the cobweb diagram. If the former approach is adopted, a second series of cobweb diagrams could be generated for each of the four composite risk prioritization scales that illustrate the nature of the underlying components. Given that different scales may be used to measure each of the factors, thresholds can be included on the cobweb diagrams to indicate when each becomes critical, or alternatively reference points can be defined that are well known to decision-makers.

The third and final stage of the framework introduces formal multi-criteria decision analysis (MCDA) into the process. MCDA is a powerful tool that gives the decisionmaker the ability to ensure consistency in both the treatment of different criteria across food-combinations as well within each food-pathogen combination. It also dramatically increases the external transparency of the ranking process, demonstrating why specific food-pathogen combinations are ranked higher/lower than others by providing an 'audit trail' of the value placed on particular prioritization factors.

The MCDA approach enables alternative opinions and priorities to be considered and can help in developing consensus. In addition, by employing a MCDA approach we have the ability to 'diagnose' decisions, for example using scenario analyses to look at how decisions might change if the values placed on various criteria were to be changed. This can be especially important in food safety decision-making where there are numerous stakeholders involved and decisions to focus on one priority over another can be contentious. At the same time, however, the application of such a formal analysis requires a greater degree of commitment from decision-makers to articulate their value structure, including the prioritization factors they consider most important, the value 
placed on each prioritization factor, etc. Clearly, the utility of such an approach is reliant on considerable 'buy-in' on the part of decision-makers.

The decision-making environment that we work within is surprisingly complex. Not only are there multiple factors influencing the decision, but there are potentially many different food-pathogen combinations. Moreover, the factors in the framework are quite possibly measured in different units; indeed the attributes we suggest above for each of the four prioritization factors are measured quite differently. As such, developing a single measure or metric to use in prioritizing risks becomes rather difficult. While no single metric is clearly preferred, results could be sensitive to the chosen metric.

Different types of multi-criteria or attribute decision analysis methods have been developed to contend with these problems (see Baker et al. 2001 and references therein for discussion). Two methods stand out as useful here, namely multi-attribute utility theory and outranking analysis, both of which are discussed below:

\section{- Multi-Attribute Utility Theory:}

Multi-attribute utility theory (MAUT) is a convenient means to aggregate across different factors in a multi-criteria decision analysis (MCDA) setting. MAUT is especially useful when the factors in the decision environment are measured in different units or dimensions. MAUT is undertaken in multiple steps, as follows:

1. Determine the set of factors (or criteria) that affect the decision.

2. Determine the weight to be assigned to each decision factor. These weights can be thought of as importance weights and will be the same across all options or alternatives being considered.

3. Develop a utility function for each factor from information in the relevant literature or purposefully designed surveys. Each factor's utility function transforms the factor's value into a utility score bound between zero and one. Utility functions can be increasing or decreasing in the value of the relevant factor, and can be curvilinear as well (but are typically assumed to be monotonic in the factor's value).

4. For each alternative, calculate each factor's utility score based on that factor's value in the respective alternative.

5. Use the weights from step two to calculate an overall utility score for each alternative as a weighted sum over each factor's individual utility score.

6. Compare the options and choose the option with the highest score.

MAUT is useful when there are many different factors and alternatives to consider. Moreover, the weights and shape of the utility function can be constructed to reflect objective information and subjectively held 
information/beliefs. If measurement of the factors is uncertain, or data is of questionable quality, one may resort to using ordinal-scaled data and the simple multi-attribute rating technique (SMART). However, analysis with fuzzy, uncertain or ordinal data is fraught with difficulties (see Kangas et al., 2001) that may limit MAUT applicability and value. In these instances, other methods are often used. One such method in this respect is outranking.

\section{- Outranking Analysis:}

Outranking methods (Roy, 1990; 1996; Brans et al., 1985; 1986) represent a different school of thought with respect to multi-criteria decision analysis. These methods are based on the principles of pair-wise comparison and unlike the value/utility based methods do not try to develop an overall value/utility function or score. Rather, the performance of each option in a criterion is compared to the other options using the scale that is natural to that criterion. It should be noted that given the pair-wise comparison nature of the approach, these approaches are most suited to problems with discrete choices.

There are two main families of outranking methods: ELECTRE (Roy, 1990); and PROMETHEE (Brans et al., 1985). In outranking methods, an alternative "a" outranks another alternative "b" if, taking into account the preferences of the decision makers and the performance of "a" across all the criteria, there is a strong enough argument to support the conclusion that "a” is at least as good as "b" and no strong argument to the contrary. The primary difference in the outranking methods is in their incorporation of decision maker preference into the problem and the synthesis of the individual outranking relationships across all the criteria in order to provide a measure of the strength of the argument in favor of one option vs. another.

Outranking approaches have an advantage over other multi-criteria methods primarily due to the fact that they more closely resemble actual decision making processes and are in that sense easier to operationalize within a community that is as yet not accustomed to formal decision analysis approaches. The more natural structure is captured by the fact that these methods do not force the translation of different scales and units of measurement in different criteria into a single common measure for purposes of comparison. Rather, outranking approaches focus on comparing options within each criterion. In essence, comparing apples with apples, and oranges with oranges rather than trying to make apples and oranges comparable from the start.

The development of utility or value functions that apply across criteria, which is a central part of the utility based approaches, can be a difficult task to accomplish. Conversely, outranking approaches, and PROMETHEE in particular, requires the decision-maker to articulate only their preferences within each criteria. In addition, outranking approaches are not compensatory meaning that, unlike utility or value based approaches, they do not allow very poor performance in one criterion to be compensated for by very strong performance in another criterion. 
There are several distinct steps that need to be completed in order to implement the PROMETHEEE MCDA approach. These include:

1. Identifying the options (in this case the list of food-pathogen combinations).

2. Defining the criteria (the measures against which the interventions will be judged).

3. Constructing the performance matrix (defining how each intervention performs on each criterion).

4. Determining the preference relationships (deciding how much better something has to be in a certain criteria in order for it to be considered "better" than an alternative as well as the importance of each of the criteria to the decision maker).

5. Ranking the alternatives (conducting the pair-wise comparisons within the criteria and producing the overall ranking across the entire matrix by applying the appropriate algorithms).

The three-stage process outlined above produces a 'List A' of priority food-pathogen combinations according to some aggregate of the four risk prioritization factors. However, we see the output as not being a ranked listing of food-pathogen combinations per se, but rather the identification of sub-sets of issues that are judged 'high', 'medium' or 'low' priority according to some predefined thresholds. At the same time, we would suggest that the three levels of output, namely information cards, cobweb diagrams and numerical food-pathogen prioritizations are presented side-by-side, aiding interpretation of the results and discussion and debate among decision-makers as to priority actions and the basis on which such prescriptions are made.

Having derived the 'List A' of priority food-pathogen combinations, it is critical that 'List B' and also (ideally) 'List C' be developed. 'List B' brings in feasibility analysis by ranking those combinations where practical actions having a significant impact are feasible; in other words, it is possible to do something about the issue within the realm of known actions. In so doing, account might be taken of interventions that are socially and/or politically acceptable, involve costs that are within available budgets, etc. Thus, 'List B' represents a vetted version of 'List A'; combinations where interventions are not known or not considered feasible are excluded from 'List B'. Food-pathogen combinations where not enough is known to identify any or few feasible interventions are included in 'List C'. This list highlights areas with significant uncertainty in the qualitative or quantitative information available for use in prioritization. High levels of uncertainty might act as a 'warning' to decision-makers in interpreting the results, and also provide some indication of where further research is needed to enhance the precision of the risk prioritization exercise. 


\section{CONCLUSIONS:}

With the more widespread and increasingly rigorous application of risk analysis to foodborne risks, policy-makers face an increasingly complex decision environment in which priorities have to be set between competing issues. A number of analytical frameworks have been developed to support risk management decisions, most of which focus on the public health implications of food-borne risks, setting priorities according to measures of health outcomes, and in some cases also the associated economic costs. However, risk prioritization is increasingly informed and influenced by a wider range of factors, including consumer perceptions and wider social-ethical concerns. It is not evident that existing analytical frameworks are amenable to multi-factorial decisions of this type and there is an evident need to develop new and more flexible approaches.

This paper has outlined a structured framework for prioritizing the risks associated with food-borne pathogens in a multi-factorial environment. The MFRPF provides a flexible instrument that compares and contrasts risks along four dimensions, namely public health, consumer perceptions and acceptance, market-level effects and social sensitivity. Through three analytical stages, the framework characterizes and compares risks according to these four factors and establishes numerical priorities: across pathogens for a particular food, across foods for a particular pathogen and/or across specific foodpathogen combinations. In so doing, the MFRPF enables each of the risk prioritization factors, and their constituent attributes, to be quantified using a range of measures on the basis of the specific characteristics of each construct, the nature and level of available data, etc. This flexibility enables the framework to be employed even in contexts where the quantity and/or quality of data are limited.

In addition to establishing a multi-factorial prioritization of food-borne risks in 'List A' through use of information cards, cobwebs, and Multiple Criteria Decision Analysis, the MFRPF enables priority risks to be "sifted" according to the feasibility of available interventions, for example in terms of efficacy, economic costs given available resources and/or social and political acceptability, through the development of 'List B'. Further, the inherent uncertainties associated with the established priorities can be "flagged" in 'List C' in order to inform decision-makers as to the need for caution in interpretation. In its structure, the framework does not aim to make risk management decisions, but rather intends to support such decisions and to make risk priority-setting more transparent and accountable, as well as more amenable to communication. Thus, we would shy away from the framework being used to produce a strictly ordered prioritization of risks, although it could certainly be employed in this way.

This framework has the potential to be a major advance on existing approaches to risk prioritization. Thus, there is an undoubted need for the framework to be tested. In so doing, our ideas will develop and each element of the platform can be refined. We envisage constructing a beta version of the framework that incorporates at least two pathogens and, across these, the predominant foods where these pathogens are a significant risk. This will enable the framework to be implemented at both the foodpathogen combination level and also across foods and/or pathogens. In so doing, critical 
operational issues can be identified and addressed, while illustrating the realities of developing a full-blown framework that incorporates the full range of foods and pathogens that must be addressed by decision-makers at the current time.

\section{REFERENCES:}

Baker, D., D. Bridges, R. Hunter, G. Johnson, J. Krupa, J. Murphy, and K. Sorenson. (2001) Guidebook to Decision-Making Methods. US Department of Energy, Washington DC.

Batz, M.B., S. Hoffmann, A.J. Krupnick, J.G. Morris, D.M. Sherman, M.R. Taylor and J.S. Tick (2004) Identifying the Most Significant Microbiological Food-Borne Hazards to Public Health: A New Risk Ranking Model. Food Safety Research Consortium Discussion Paper Series No. 1.

Batz, M.B., M.P. Doyle, J.G. Morris, J. Painter, R. Singh, R.V. Tauxe, M.R. Taylor, D.M.A. Lo Fo Wong (2005) Attributing Illness to Food. Emerging Infectious Diseases, 11, 993-999.

Brans, J.P. and P. Vincke (1985) A preference Ranking Organization Method: The PROMETHEE Method. for MCDM. Management Science, 31 (6) 647-656.

Brans, J.P., P. Vincke and B. Mareschal (1986). How to Select and How to Rank Projects: The Promethee Method. European Journal of Operational Research, 24, 228238

Dijksterhuis, G.B. and J.C. Gower (1991) The Interpretation of Generalized Procrustes Analysis and Allied Methods. University of Lediden, Leiden.

European Commission (2002) Risk Assessment of Foodborne Bacterial Pathogens: Quantitative Methodology Relevant for Human Exposure Assessment. Health and Consumer Protection Directorate-General Directorate C - Scientific Opinions, C1 Follow-Up and Dissemination of Scientific Opinions, Preliminary Report. Available at: http://europa.eu.int/comm/food/fs/sc/ssc/out252_en.pdf.

FAO/WHO (2002) Principles and Guidelines for Incorporating Microbiological Risk Assessment in the Development of Food Safety Standards and Related Texts. Report, Joint FAO/WHO consultations Kiel, 18. - 22. March 2002, Kiel, Germany.

Fischer, A.R.H., A.E.I. de Jong, R. de Jonge, L.J. Frewer and M.J. Nauta. (2005) Improving Food Safety in the Domestic Environment: The Need for a Trans-Disciplinary Approach. Risk Analysis, 25, 503-517

Fife-Schaw, C.R. and G. Rowe (1996) Public Perceptions of Everyday Food Hazards: A Psychometric Study. Risk Analysis, 16, 487-500. 
Fife-Schaw, C. and G. Rowe (2000) Extending the Application of the Psychometric Approach for Assessing Public Perceptions of Food Risk: Some Methodological Considerations. Journal of Risk Research, 3 (2), 167-179.

Fischoff, B., P. Slovic, P., S. Lichtenstein, S. Read and B. Combs (1978) How Safe is Safe Enough? A Psychometric Study of Attitudes Towards Technological Risks and Benefits. Policy Sciences, 9, 127-152.

Frewer, L.J., R. Shepherd and P. Sparks (1994) Biotechnology and Food Production: Knowledge and Perceived Risk. British Food Journal, 96, 26-32.

Frewer, L.J., C. Howard and R. Shepherd (1997) Public Concerns about General and Specific Applications of Genetic Engineering: Risk, Benefit and Ethics. Science, Technology and Human Values, 22, 98-124.

Frewer, L.J., C. Howard, D. Hedderley and R. Shepherd (1998a) Methodological Approaches to Assessing Risk Perceptions Associated with Food-Related Hazards. Risk Analysis, 18, 95-102.

Frewer, L.J., C. Howard and R. Shepherd (1998b) Understanding Public Attitudes to technology. Journal of Risk Research, 1 (3), 221-235.

Gold, M.R., D. Stevenson and D.G. Fryback (2002) HALYs and QALYs and DALYs, Oh My: Similarities and Differences in Summary Measures of Population Health. Annual Review of Public Health, 23, 115 - 134.

Gower, J.C. (1975) Generalized Procrustes Analysis. Psychometrica, 40, 33-51.

Gower, J.C. and G.B. Dijksterhuis (2004) Procrustes Problems. Oxford University Press, Oxford.

Havelaar, A. (2002) CARMA - Campylobacteriosis Risk Management and Assessment. Microbiological Laboratory for Health Protection, National Institute for Public Health and the Environment (RIVM), Bilthoven, the Netherlands.

Health Canada (2000) Health Canada Decision-making Framework for Identifying, Assessing and Managing Health Risks. Health Canada, Ottawa.

Henson, S.J. (2006) Economic Analysis of Reductions in Incidence of Salmonellosis and Campylobacteriosis due to Implementation of HACCP Advantage in Non-Federally Registered Poultry Processing Facilities. Department of Food, Agricultural and Resource Economics, University of Guelph.

Henson, S.J. and M. Mazzocchi (2002) Impact of the BSE Crisis on UK Agribusiness: Results of an Event Study of Equity Prices. American Journal of Agricultural Economics, 84 (2), 370-386. 
Henson, S., M. Annou, J. Cranfield, J. Ryks and D. Herath (2006) Understanding Consumer Attitudes towards Food Technologies in Canada. Unpublished manuscript, Department of Food, Agricultural and Resource Economics, University of Guelph.

Institute of Medicine, National Academies. In Press. Seafood Choices: Balancing Benefits and Risks. Washington, DC: The National Academies Press.

Kangas, A., J. Kangas and J. Pykäläinen (2001) Outranking Methods as Tools in Strategic Natural Resources Planning. Silva Fennica 35 (2), 215-227.

Kuchler, F. and E. Golan (1999) Assessing Values to Life: Comparing Methods for Valuing Health Risks. Agricultural Economic Report No. 784, ERS, USDA, Washington DC.

Mangen, M-J.J., A.H. Havelaar, K.P. Poppe and G.A. de Wit (Forthcoming) Cost-Utility Analysis to Control Campylobacter on Chicken Meat - Dealing with Data Limitations. Risk Analysis.

Moore, M. and W. Viscusi (1988) The Quality-Adjusted Value of Life. Economic Inquiry 26 (3), 369-388.

Murray, C.J.L. and A.K. Acharya (1997) Understanding DALYs. Journal of Health Economics 16, $703-730$.

Nauta, M.J. (2001) Quantitative Microbiological Risk Assessment and its Application in an Exposure Assessment of Bacillus cereus in a REPFED. National Institute of Public Health and the Environment (RIVM), Report No. 149106 007, Bilthoven, the Netherlands.

NRC (1996) Understanding Risk: Informing Decisions in a Democratic Society. National Academies Press, Washington Dc.

NZFSA (2000) Food Administration in New Zealand - A Risk Management Framework for Food Safety. Joint Ministry of Health and Ministry of Agriculture and Forestry Food Harmonization Project. Available at: http://www.moh.govt.nz.

OMAFRA (2003) Food Safety Universe Database - A Semi-Quantitative Risk Assessment Tool. Draft, v7, Ontario Ministry of Agriculture and Food, 2003.

Renn, O. and P. Graham (2005) Risk Governance: Towards an Integrative Approach. International Risk Governance Council, White Paper No. 1. Available at: http://www.irgc.org/_cgidata/mhscms/_images/12326-3-3.pdf.

Research Triangle Institute (1988) Estimating the Value of Consumer's Loss from Foods Violating the FD\&C Act. Prepared for US Food and Drug Administration, FDA Contract No. 233-86-2097. 
Ross, T. and J. Sumner (2002) A Simple, Spreadsheet-Based, Food Safety Risk Assessment Tool. International Journal of Food Microbiology, 77, 39-53.

Roy, B. (1990). The Outranking Approach and the Foundations of the ELECTRE Methods. In: Costa, B. (ed.) Readings in Multiple Criteria Decision Aid. Springer-Verlag, Berlin.

Roy, B. (1996). Multicriteria Methodology for Decision Aiding. Kluwer Academic Publishers, Dordrecht.

Slovic, P., B. Fischoff and S. Lichtenstein, S. (1980) Facts and Fears: Understanding Perceived Risk. In: Schwing, R.C. and Albers, W.A. (eds). Societal Risk Assessment: How safe is Safe Enough? Plenum Press, New York.

Slovic, P. (2000) The Perception of Risk. Earthscan, London.

Sparling, D. and J.A. Caswell (2006) Risk Management in the Integrated NAFTA Market: Lessons from the Case of BSE. Review of Agricultural Economics

Van Gerwen, S.J.C., M.C. te Giffel, K. van 't Riet, R.R. Beumer and M.H. Zwietering (2000) Stepwise Quantitative Risk Assessment as a Tool for the Characterization of Microbiological Food Safety. Journal of Applied Microbiology, 88, 938-951. 